\title{
Pituitary Adenylate Cyclase-Activating Polypeptide Modulates Dendritic Spine Maturation and Morphogenesis via MicroRNA-132 Upregulation
}

\author{
๑DAtsuko Hayata-Takano, ${ }^{1,2 \star}$ Toshihiko Kamo, ${ }^{1 \star}$ Harui Kijima, ${ }^{1}$ Kaoru Seiriki, ${ }^{1,3}$ @Katsuya Ogata, ${ }^{1}$ ○Yukio Ago, ${ }^{1,4}$ \\ 다akanobu Nakazawa, ${ }^{1,5}$ Yusuke Shintani, ${ }^{1}$ Kosuke Higashino, ${ }^{1}$ @Kazuki Nagayasu, ${ }^{1}$ №rihito Shintani, ${ }^{1}$ \\ (D)Atsushi Kasai, ${ }^{1}$ D James A. Waschek, ${ }^{6}$ and ${ }^{D}$ Hitoshi Hashimoto ${ }^{1,2,7,8}$ \\ ${ }^{1}$ Laboratory of Molecular Neuropharmacology, Graduate School of Pharmaceutical Sciences, Osaka University, Osaka 565-0871, Japan, ${ }^{2}$ United Graduate \\ School of Child Development, Osaka University, Kanazawa University, Hamamatsu University School of Medicine, Chiba University, and University of \\ Fukui, Osaka 565-0871, Japan, ${ }^{3}$ Institute for Transdisciplinary Graduate Degree Programs, Osaka University, Osaka 565-0871, Japan, ${ }^{4}$ Laboratory of \\ Biopharmaceutics, Graduate School of Pharmaceutical Sciences, Osaka University, Osaka 565-0871, Japan, ${ }^{5}$ Department of Pharmacology, Graduate School \\ of Dentistry, Osaka University, Osaka 565-0871, Japan, ${ }^{\top}$ Intellectual Development and Disabilities Research Center, David Geffen School of Medicine, University \\ of California-Los Angeles, Los Angeles, California 90095, ${ }^{7}$ Division of Bioscience, Institute for Datability Science, Osaka University, Osaka 565-0871, Japan, and \\ ${ }^{8}$ Transdimensional Life Imaging Division, Institute for Open and Transdisciplinary Research Initiatives, Osaka University, Osaka 565-0871, Japan
}

Alterations in pituitary adenylate cyclase-activating polypeptide (PACAP), a multifunctional neuropeptide, and its receptors have been identified as risk factors for certain psychiatric disorders, including schizophrenia. Increasing evidence from human genetic and animal model studies suggest an association between various psychiatric disorders and altered dendritic spine morphology. In the present study, we investigated the role of exogenous and endogenous PACAP in spine formation and maturation. PACAP modified the density and morphology of PSD-95-positive spines in primary cultured hippocampal neurons. Notably, PACAP increased the levels of microRNA (miR)-132 and decreased expression of corresponding miR-132 target genes and protein expression of p250GAP, a miR-132 effector known to be involved in spine morphology regulation. In corroboration, PSD-95-positive spines were reduced in PACAP-deficient $\left(P A C A P^{-/-}\right)$mice versus WT mice. Golgi staining of hippocampal CA1 neurons revealed a reduced spine densities and atypical morphologies in the male $P A C A P^{-/-}$mice. Furthermore, viral miR-132 overexpression reversed the reduction in hippocampal spinal density in the male $P A C A P^{-1-}$ mice. These results indicate that PACAP signaling plays a critical role in spine morphogenesis possibly via miR-132. We suggest that dysfunction of PACAP signaling may contribute to the pathogenesis of neuropsychiatric disorders, at least partly through its effects on spine formation.

Key words: CA1; dendritic spine; miRNA; morphogenesis; PACAP

Significance Statement

Pituitary adenylate cyclase-activating polypeptide (PACAP) signaling dysfunction and dendritic spine morphology alterations have recently been suggested as important pathophysiological mechanisms underlying several psychiatric and neurological disorders. In this study, we investigated whether PACAP regulates dendritic spine morphogenesis. In a combination of pharmacological and viral gain- and loss-of-function approaches in vitro and in vivo experiments, we found PACAP to increase the size and density of dendritic spines via miR-132 upregulation. Together, our data suggest that a dysfunction of PACAP signaling may contribute to the pathogenesis of neuropsychiatric disorders, at least partly through abnormal spine formation.

\section{Introduction}

Pituitary adenylate cyclase-activating polypeptide (PACAP) exerts multiple activities as a neurotransmitter, neuromodulator, and neurotrophic factor. Previously, we demonstrated notable psychomotor abnormalities in PACAP-deficient $\left(P A C A P^{-1-}\right)$ mice, most of which were reversed by the application of atypical 
antipsychotics (Hashimoto et al., 2001, 2009; Tajiri et al., 2012; Ago et al., 2013), and association of PACAP gene single nucleotide polymorphisms with schizophrenia (Hashimoto et al., 2007). More recently, some studies have suggested that PACAP may also be related to the pathogenesis of some other psychiatric disorders, such as attention deficit hyperactivity disorder and post-traumatic stress disorder (Tanaka et al., 2006; Ressler et al., 2011; Shibasaki et al., 2015). Together, these findings suggest that a dysfunction in PACAP signaling may be involved in the pathogenesis of psychiatric disorders, including schizophrenia and attention deficit hyperactivity disorder. We have recently demonstrated that PACAP induces axonal outgrowth in primary cultured neurons (Ogata et al., 2015). However, the mechanisms by which dysfunctional PACAP signaling may contribute to the genesis of neuropsychiatric disorders remain unclear.

Recent studies have suggested that abnormal dendritic spines may contribute to the pathogenesis of several psychiatric disorders (Kaufmann and Moser, 2000; Penzes et al., 2011; Moyer et al., 2015). Dendritic spines are the sites where most excitatory glutamatergic synapses in the mammalian brain are localized and represent the postsynaptic compartment of these synapses. The regulation of the dendritic spine number, size, and shape is important for the plasticity of the dendritic synapses, as well as learning and memory (Lai and Ip, 2013; Bailey et al., 2015). Supporting this hypothesis, postmortem neuropathological studies have found altered dendritic spine density on cortical pyramidal neurons in individuals with schizophrenia (Glausier and Lewis, 2013). Several mouse strains mutant for the genes associated with psychiatric disorders show abnormal behavior and dendritic spine loss (Fénelon et al., 2013; Qiao et al., 2016). Therefore, unraveling the molecular mechanisms underlying the formation and maintenance of the dendritic spines is critical for better understanding the mechanisms underlying psychiatric disorders.

MicroRNAs (miRNAs) are important post-transcriptional modulators of gene expression, suppressing the levels of several proteins through cleavage of their encoding mRNA (Follert et al., 2014). An increasing number of studies suggest that numerous specific miRNAs play critical roles in various aspects of dendritic spine morphogenesis, including plasticity, synaptogenesis, or synaptic morphology alterations (Schratt, 2009; Olde Loohuis et al., 2012; Follert et al., 2014; Ye et al., 2016). Moreover, miRNAs are crucial gene expression regulators in the phenotypic heterogeneity of psychiatric disorders (Beveridge and Cairns, 2012). Recent studies have found that neurotrophic factors, such as BDNF, GDNF, and NGF, induce expression of several miRNAs (Schratt et al., 2006; Retamales-Ortega et al., 2017; Roser et al., 2018), suggesting that neural activity affects miRNA expression via external soluble factors. However, the molecular mechanisms underlying neural activity-regulated miRNA expression remain generally unclear.

In this study, we aimed to examine whether PACAP signaling regulates synaptic morphology and to elucidate the mechanisms

JP18dm0207061h0002, and JP18am0101084, Funding Program for Next Generation World-Leading Researchers Grant LS081, Program for Advancing Strategic International Networks to Accelerate the Circulation of Talented Researchers Grant S2603, and Ministry of Education, Culture, Sports, Science and Technology KAKENHI Grant JP18H05416. This work was also supported in part by the Center for Medical Research and Education, Graduate School of Medicine, Osaka University.

The authors declare no competing financial interests.

${ }^{*}$ A.H.-T. and T.K. contributed equally to this work.

Correspondence should be addressed to Atsuko Hayata-Takano at a-hayata@phs.osaka-u.ac.jp or Hitoshi Hashimoto at hasimoto@phs.osaka-u.ac.jp.

https://doi.org/10.1523/JNEUROSCI.2468-18.2019

Copyright $\odot 2019$ the authors by which this effect may be achieved. We departed from the wellknown role of miRNAs in dendritic morphogenesis and plasticity, to explore whether PACAP may impact on miRNAs biology to regulate synaptic morphology.

\section{Materials and Methods}

Animals. Generation of $P A C A P^{-/-}$mice by a gene-targeting technique has been previously reported (Hashimoto et al., 2001). PACAP ${ }^{-/-}$mice were successively backcrossed to Crlj:CD1 mice (Charles River) at least 12 times. All WT and $P A C A P^{-/-}$mice used were obtained from the intercross of animals heterozygous for the mutant PACAP gene. All experiments were conducted on 8- to 9-week-old male mice, group-housed (4-6 per cage) with a $12 \mathrm{~h}$ light-dark cycle (light on at 8:00 A.M.) at controlled room temperature $\left(22 \pm 1^{\circ} \mathrm{C}\right)$. Pelleted food (CMF, Oriental Yeast) and water were available ad libitum. All experiments were conducted at the same time each day, and different mice were used in each experiment. All animal care and handling procedures were performed according to the Guidelines for the care and use of laboratory animals, validated by the Japanese Pharmacological Society, and approved by the Animal Care and Use Committee of the Graduate School of Pharmaceutical Sciences, Osaka University. All efforts were made to minimize the number of animals used.

Drugs. PACAP (PACAP-38) was purchased from Peptide Institute and human recombinant BDNF from Peprotech. U0126, K252a, FK-506, 4-aminopyridine (4-AP), and $1(\mathrm{~S}), 9(\mathrm{R})$-(-)-bicuculline methiodide (bicuculline) were purchased from Sigma-Aldrich. H89 and GF109203X were purchased from Tocris Bioscience. PACAP6-38, H89, GF109203X, U0126, K252a, and FK506 were applied 30 min before the addition of PACAP or BDNF.

Preparation of primary cultured hippocampal neurons. Primary cultured hippocampal neurons were prepared from embryonic day 16.5 (E16.5) mouse pups, as described previously (Ogata et al., 2015). Gestating mice were deeply anesthetized by intraperitoneal injection of a mixture of medetomidine hydrochloride $(0.75 \mathrm{mg} / \mathrm{kg}$ body weight), midazolam ( $4 \mathrm{mg} / \mathrm{kg})$, and butorphanol tartrate $(5 \mathrm{mg} / \mathrm{kg})$, and embryos were removed. Hippocampi were isolated, the tissue dissociated, and the cells were plated in Neurobasal medium (Invitrogen) supplemented with B27 (2\%; Invitrogen), L-glutamine (2 mM), $100 \mathrm{U} / \mathrm{ml}$ penicillin, and 0.1 $\mathrm{mg} / \mathrm{ml}$ streptomycin (all from Nacalai Tesque), at $2.5 \times 10^{4}$ cells per well in 24-well dishes containing glass coverslips coated with poly-L-lysine. Two days after plating, $10 \mathrm{~mm}$ ara-C (catalog \#C1768, Sigma-Aldrich) was added to prevent glial cell proliferation.

Immunostaining of primary hippocampal cells and brain slices. The procedure was performed as previously described (Ogata et al., 2015). For neuronal labeling, primary cultured hippocampal neurons were transduced with CMV-tdTomato or CMV-Venus lentivirus and fixed with $4 \%$ PFA for $10 \mathrm{~min}$ at room temperature. Primary neurons or brain coronal sections were then washed with PBS, followed by an incubation in $0.2 \%$ Triton X-100 in PBS for 5 min. After three washes in $0.2 \%$ Triton X-100 in PBS, cells were incubated for $2 \mathrm{~h}$ at room temperature in a corresponding primary antibody solution. The primary antibodies used were a mouse monoclonal anti-PSD-95 antibody (1:500; catalog \#AB9708, RRID:AB_2092543, Millipore) and a rabbit polyclonal anti-DsRed antibody (1:1000; catalog \#632496, RRID:AB_10013483, Takara Bio) or a rabbit polyclonal anti-GFP antibody (1:500; catalog \#598, RRID: AB_591819, MBL) diluted in $0.2 \%$ Triton X-100 in PBS supplemented with 3\% BSA. For predendritic and postdendritic spine labeling, the primary antibodies were used a rabbit polyclonal anti-PSD-95 antibody (1:500; catalog \#3450S, RRID:AB_2292883, Cell Signaling Technology) and a mouse monoclonal anti-synaptophysin antibody (1:2000; catalog \#611880, RRID:AB_399360, BD Biosciences) diluted in 0.2\% Triton $\mathrm{X}-100$ in PBS supplemented with 3\% BSA. After three washes with $0.2 \%$ Triton X-100 in PBS, cells were incubated for $30 \mathrm{~min}$ at room temperature in a secondary antibody solution consisting of anti-mouse or antirabbit IgG coupled to Alexa-594 (magenta, 1:1000 dilution; Invitrogen) and anti-mouse or anti-rabbit IgG coupled to Alexa-488 (green, 1:1000 dilution; Invitrogen) in $0.2 \%$ Triton X-100 in PBS with 3\% BSA. After three washes, cell-containing coverslips were mounted on glass slides 
with Fluoromount (Diagnostic BioSystems) and dried before imaging. Fluorescent images were captured using an Olympus FluoView FV1000 confocal microscope (Olympus). The analysis of the images was performed in a blinded fashion using ImageJ software (National Institutes of Health).

Cloning of lentiviral vectors. The RFP reporter sequence was exchanged with the tdTomato or Venus with SalI and BamHI and inserted into the multicloning site of the RFP-QM512B vector from the SpaQ Cumate Switch system (System Bioscience) to generate CMV-tdTomatoQM512B or CMV-Venus-QM512B. To generate the CMV-miR-132venus construct, PCR-based screening of miR-132 was performed using the forward primer 5'-GAATTCAAGGCGGCCGCTCGGGCACGCC TGTTC- 3 ' and the reverse primer $5^{\prime}$-CGATGTTAACTCTAGCGCCCG TTTTCTCGCCACCT-3' by Phusion High Fidelity DNA Polymerase (New England BioLabs). The PCR product, digested with NotI and XbaI, was inserted into the CMV-Venus-QM512B construct.

Construction of miRNA sponge plasmids. miRNA sponge plasmids were constructed as previously described (Ebert et al., 2007; Edbauer et al., 2010), with minor modifications. miR-132 sponges were constructed by concatemerizing annealed oligonucleotides containing three tandem bulged-match miRNA binding sites inside the two linkers (miR-132 sponge; 5'-GGCCGCCGACCATGGCTAGGACTGTTACATCATCGA CCATGGCTAGGACTGTTACATCATCGAC CATGGCTAGGACTGTTAC-3' and 5' $^{\prime}$-TC GAGTAACAGTCCTAGCCATGGTCGATGA TGTAACAGTCCTAGCCATGGTCGATGAT GTAACAGTCCTAGCCATGGTCGGC-3') containing restriction sites for cloning. miR-132 scramble sponges were constructed as a cassette by synthetic oligonucleotide ( $5^{\prime}$-CG GCATGGACGAGCTGTACAAGTAAAGCGG CCGCGACTGTATGCTAGCGACACTGCAT CATGACTGTATGCTAGCGACACTGCATC ATGACTGTATGCTAGCGACACTGCTCGA CCCGAGCTGTACAAGTAAAGCGGCCG CGAC- $3^{\prime}$ ), containing restriction sites for cloning. After ligation, the appropriate size concatemers were PCR amplified and cloned into the $3^{\prime}$-UTR of the tdTomato or the Venus cDNAs driven by a CMV promoter into pcDNA3-CMV vector digested with XhoI and Sall.

Lentiviral production, concentration, and titration. Briefly, $4.0 \mu \mathrm{g}$ of lentiviral vector was transfected with $20.0 \mu \mathrm{g}$ of mixed shuttle constructs to Lenti-X 293T cells (Clontech) in 10 $\mathrm{cm}$ dishes using polyethylenimine ("Max," MW 40,000; Polysciences). After 12 h incubation, culture supernatant was changed fresh DMEM with 5\% GlutaMAX (Sigma-Aldrich). After $36 \mathrm{~h}$ incubation, the culture supernatant was collected. Lentiviral vector-containing media were filtered through a $0.45 \mu \mathrm{m}$ PVDF filter and ultracentrifuged at $23,000 \mathrm{rpm}$ using an SW-28 rotor (Beckman-Coulter) for $2 \mathrm{~h}$. After ultracentrifugation, the supernatant was removed, and the precipitates were resolved in $30 \mu \mathrm{l}$ sterile PBS. Lentiviral vectors were dispensed and stored at $-80^{\circ} \mathrm{C}$. The titer of the lentiviral vector solution was estimated using Global UltraRapid Lentiviral Titer Kit (catalog \# LV961A-1, System Bioscience).

Lentiviral transduction of mouse primary hippocampal cells. A total of $0.6 \mu \mathrm{l}$ of CMVtdTomato-QM512B or CMV-Venus-QM512B lentivirus was added to primary hippocampal cells grown in a 24 -well dish at day 14 of in vitro culture (DIV14). Incubation was performed overnight, and the medium was changed the following day. After incubation for a total of
Table 1. Primers used for qRT-PCR analysis

\begin{tabular}{|c|c|c|}
\hline Gene & Direction & Oligonucleotide sequence $\left(5^{\prime} \rightarrow 3^{\prime}\right)$ \\
\hline \multirow[t]{2}{*}{ Gapdh } & Forward & GTGTTCCTACCCCCAATGTG \\
\hline & Reverse & TACCAGGAAATGAGCTTGAC \\
\hline \multirow[t]{2}{*}{ P250GAP } & Forward & ACCAACTCAGTGCCAAAACC \\
\hline & Reverse & AACCCAGAATTGAGGAGGTG \\
\hline \multirow[t]{2}{*}{ Ankrd11 } & Forward & GGAAGGAGGTGAGAGAACGA \\
\hline & Reverse & GGGACCCTGCTTCTCTGTG \\
\hline \multirow[t]{2}{*}{ Fkbp2 } & Forward & GCACTGGCCAGGTTATCAAG \\
\hline & Reverse & СTCCCCGCTCTCCATACC \\
\hline \multirow[t]{2}{*}{ Dnmt3a } & Forward & GAGGGAACTGAGACCCCAC \\
\hline & Reverse & CTGGAAGGTGAGTCTTGGCA \\
\hline \multirow[t]{2}{*}{ Mecp2 } & Forward & CAAACAGAGAGGAGCCTGTGGACAG \\
\hline & Reverse & TTTATTTCAGTTAATCGGGAAGCTTTG \\
\hline \multirow[t]{2}{*}{ Gmfb } & Forward & TCGTACCCGCTCTGCTTTAT \\
\hline & Reverse & TTGTTCTTACTCCCAGCGTAC \\
\hline \multirow{2}{*}{ Dpys/3 } & Forward & CAGCCTGGGAATAGATGGAA \\
\hline & Reverse & TTCTGGGCAGTGCTAAAGGT \\
\hline \multirow[t]{2}{*}{ Sirt1 } & Forward & TTGCAAAGGAGCAGATTAGTAAG \\
\hline & Reverse & CTGCCACAGGAACTAGAGGACAAGA \\
\hline \multirow[t]{2}{*}{ Bdnf } & Forward & GTGACAGTATTAGCGAGTGGG \\
\hline & Reverse & GGGTAGTTCGGCATTGC \\
\hline
\end{tabular}
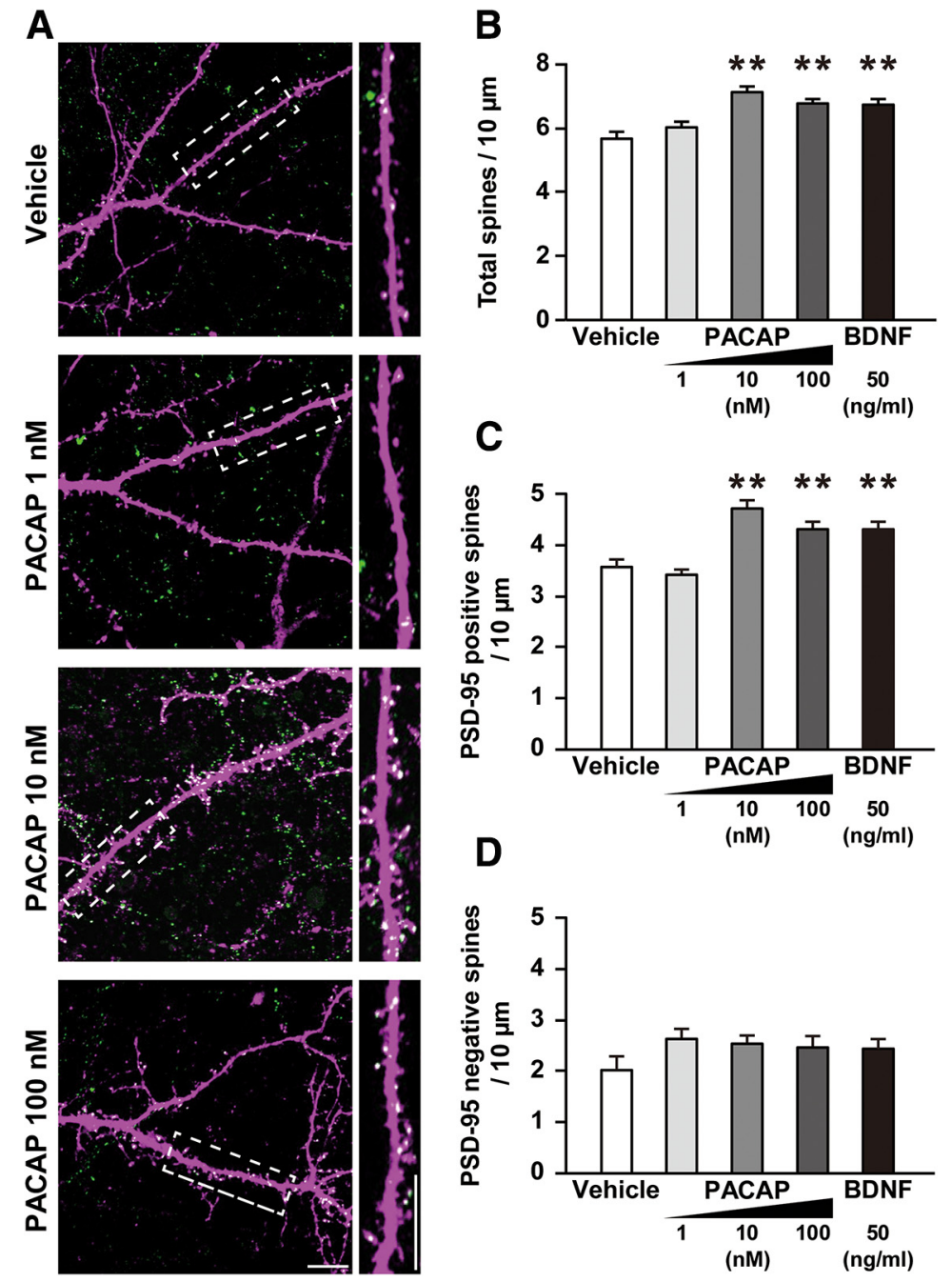

Figure 1. PACAP significantly increased dendrite spine density in the primary cultured hippocampal neurons at DIV21. $\boldsymbol{A}$, Representative fluorescence images of the primary hippocampal neuronal dendrites at DIV21. Primary hippocampal neurons were treated for $2 \mathrm{~d}$ with 1, 10, or $100 \mathrm{~nm}$ PACAP or $50 \mathrm{ng} / \mathrm{ml}$ BDNF. The cells were fixed at DIV21 and immunostained using anti-DsRed (magenta) and anti-PSD95 (green) antibodies. Magnification of the area marked with a white dot box. Scale bar, $10 \mu \mathrm{m} . \boldsymbol{B}-\boldsymbol{D}$, Quantification of the number of the total spines ( $\boldsymbol{B})$, PSD-95 positive spines $(\boldsymbol{C}$ ) and PSD-95 negative spines $(\boldsymbol{D})$. Values indicate mean \pm SEM on 60 neurons from three independent experiments. ${ }^{* *} p<0.01$ versus vehicle (one-way ANOVA followed by Tukey-Kramer test). 
A

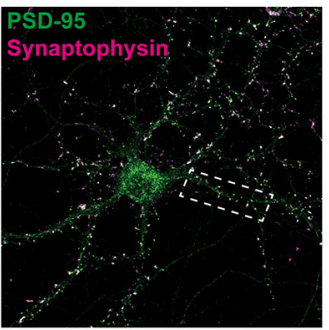

B

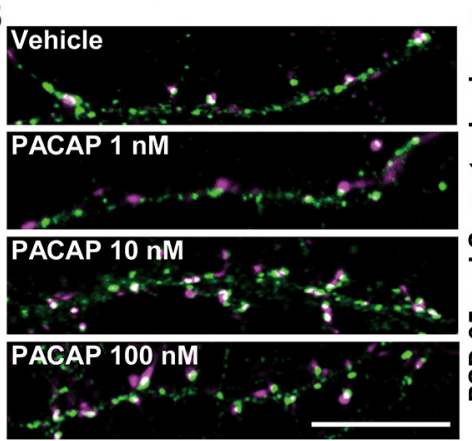

D

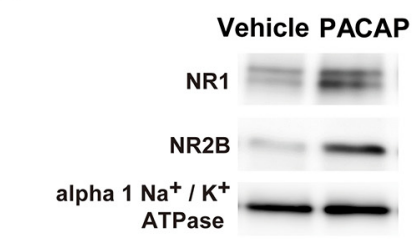

$\mathbf{F}$

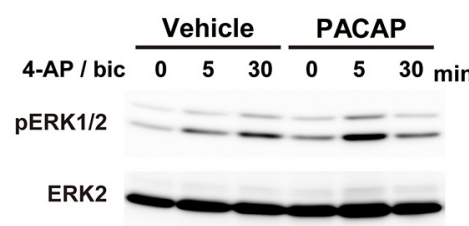

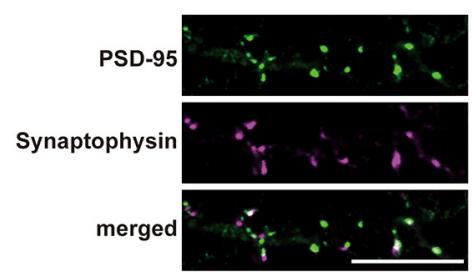

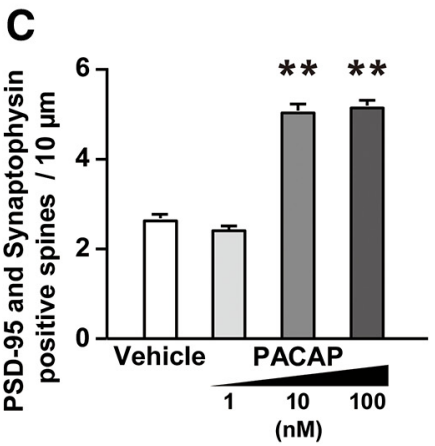

E

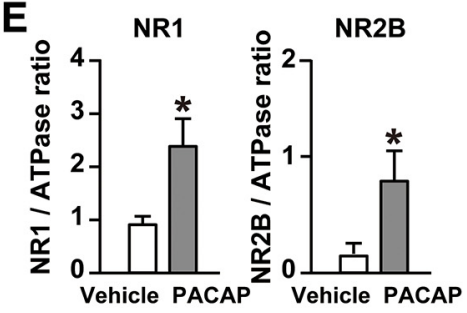

G

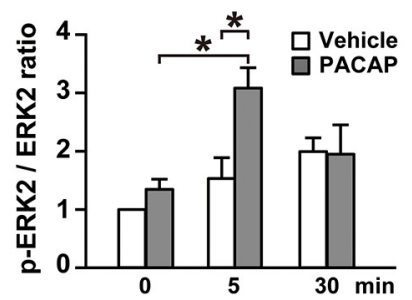

Figure 2. PACAP significantly increased the number of function synapse in the primary cultured hippocampal neurons. $\boldsymbol{A}$, Representative fluorescence images of the primary hippocampal neuronal dendrites at DIV21. The cells were fixed at DIV21 and immunostained using anti-synaptophysin (magenta) and anti-PSD95 (green) antibodies. Magnification of the area marked with a white dot box. Scale bar, $10 \mu \mathrm{m}$. B, Primary hippocampal neurons were treated for $2 \mathrm{~d}$ with 1, 10, or $100 \mathrm{~nm}$ PACAP. Scale bar, 10 $\mu \mathrm{m}$. C, Quantification of the number of PSD-95-positive spines that were apposed to synaptophysin-positive presynaptic terminals. Values indicate mean \pm SEM on 60 neurons from three independent experiments. ${ }^{* *} p<0.01$ versus vehicle (one-way ANOVA followed by Tukey-Kramer test). D, Immunoblot of cell surface biotinylated $\alpha 1$ sodium potassium ATPase, NR1, and NR2B from the primary cultured hippocampal neurons at DIV14. Surface biotinylation assay was performed after $2 \mathrm{~d}$ treatment with vehicle or $10 \mathrm{~nm}$ PACAP. E, Quantification of the cell surface expression levels of NR1 and NR2B were normalized to the levels of $\alpha 1$ sodium potassium ATPase. Values indicate mean \pm SEM from five independent experiments. ${ }^{*} p<0.05$ versus vehicle (Student's $t$ test). $\boldsymbol{F}$, Representative immunoblots showing expression of pERK1/2 and ERK2. Synaptic NMDAR activity in the primary cultured hippocampal neurons at DIV14 were treated with vehicle or $500 \mu \mathrm{m} 4-\mathrm{AP}$ and $50 \mu \mathrm{m}$ bicuculline (bic) for 5 or $30 \mathrm{~min}$ after $2 \mathrm{~d}$ treatment with vehicle or $10 \mathrm{~nm}$ PACAP. 4-AP is a potassium channel blocker, and bicuculline is a $\mathrm{GABA}_{\mathrm{A}}$ receptor blocker. $\boldsymbol{G}$, Quantification of the expression levels of pERK2 were normalized to the levels of ERK2. Values indicate mean \pm SEM from four independent experiments. ${ }^{*} p<0.05$ versus vehicle or 0 min (two-way ANOVA followed by Tukey-Kramer test).

$8 \mathrm{~d}$, cells were fixed and immunostained for a rabbit polyclonal antiDsRed antibody or a rabbit polyclonal anti-GFP antibody.

$q R T$ - PCR. For mRNA, total RNA was extracted using the guanidineisothiocyanate procedure. Reverse transcription of the total RNA $(1 \mu \mathrm{g})$ and qRT-PCR were performed as previously described (Mabuchi et al., 2004). For miRNA, total RNA extraction was performed using an miRNeasy Mini Kit (QIAGEN) according to the manufacturer's instructions, and reverse transcription was performed using a TaqMan MicroRNA Reverse Transcription Kit (Applied Biosystems). The qRTPCR was performed using GoTaq Master Mix (Promega) for mRNA. The primer sequences of the PCR cycles are specified in Table 1. The gapdh housekeeping gene was simultaneously reverse transcribed and amplified as the internal reference. The qRTPCR consisted of denaturation at $95^{\circ} \mathrm{C}$ for $10 \mathrm{~s}$, annealing at $58^{\circ} \mathrm{C}-66^{\circ} \mathrm{C}$ for $20 \mathrm{~s}$, and extension at $72^{\circ} \mathrm{C}$ for $20 \mathrm{~s}$. For miRNA, qRT-PCR was performed according to the manufacturer's instructions using either TaqMan Universal Master MixII (Applied Biosystems) with miRNA-specific TaqMan MicroRNA Assays (Applied Biosystems, snoRNA202: Assay ID001232; miR-34a: Assay ID 000426; miR34c: Assay ID 000428; miR-124: Assay ID 001182; miR-132: Assay ID 000457; miR-219: Assay ID 000552).

Surface biotinylation assay. The receptor biotinylation assay was performed using the Pierce cell surface protein isolation kit (Thermo Fisher Scientific) according to the manufacturer's instructions. The surface proteins of the mouse primary cultured hippocampal neurons at DIV14 were biotinylated with EZ-Link Sulfo-NHS-SS-biotin for $30 \mathrm{~min}$ at $4^{\circ} \mathrm{C}$. To collect the surface proteins, cells were lysed with lysis buffer and biotinylated proteins were precipitated with NeutrAvidin agarose. The collected surface proteins were added sample buffer to eluate and analyze by Western blot.

Activation of synaptic NMDA receptors in the primary cultured hippocampal neurons. Primary cultured hippocampal neurons were treated with 10 nм PACAP or saline at DIV12. After $2 \mathrm{~d}, 500 \mu \mathrm{M} 4-\mathrm{AP}$ and $50 \mu \mathrm{M}$ bicuculline were added to activate synaptic NMDA receptors in the primary cultured hippocampal neurons for 5 or $30 \mathrm{~min}$ as previously described (Nakazawa et al., 2008). The cells were collected and lysed with RIPA buffer.

Western blot analysis. Mouse primary cultured hippocampal neurons were collected and homogenized in 10 volumes of RIPA buffer containing $20 \mathrm{~mm}$ Tris- $\mathrm{HCl}, \mathrm{pH} 7.4,1 \mathrm{~mm}$ EDTA, $0.15 \mathrm{~m} \mathrm{NaCl}, 1 \%$ Nonidet P-40, 5\% glycerol, $5 \mathrm{~mm} \mathrm{~L}$-mercaptoethanol, and $1 \mathrm{~mm}$ PMSF. The homogenates were centrifuged at $8000 \mathrm{rpm}$ for $15 \mathrm{~min}$ at $4^{\circ} \mathrm{C}$. The protein concentration in the supernatant was determined using the bicinchoninic acid assay assay (Pierce), and an aliquot was mixed with SDS sample buffer. The samples were separated by $10 \%$ SDS-PAGE, transferred electrophoretically to nitrocellulose membranes, and then blocked with $1 \%$ BSA in Tris-buffered saline containing $0.05 \%$ Tween 20. After incubation with rabbit polyclonal anti-p44/42 MAPK antibody (1:500 dilution; catalog \#9102S, RRID: AB_330744, Cell Signaling Technology) or mouse monoclonal anti-p250GAP antibody (1:80,000 dilution; catalog \#AP9480b, RRID:AB_10612374, Abgent), the membranes were then incubated with HRP-conjugated anti-rabbit IgG (1:5000 dilution; Cappel Laboratories) or HRP-conjugated anti-mouse IgG (1:2000 dilution; Cappel Laboratories). For surface biotinylated assay, the membranes were incubation with mouse monoclonal antiNMDAR1 antibody (1:300 dilution; catalog \#MAB1586, RRID: AB_2279138, Millipore), mouse monoclonal anti- $\alpha 1$ sodium potassium ATPase (1:1000 dilution; catalog \#ab7671, RRID: AB_306023, Abcam) or rabbit polyclonal anti-NMDAR2B antibody 
(1:500 dilution; catalog \#AB1557p, RRID: AB_90772, Millipore). For synaptic NMDA receptor activation assay, the membranes were incubation with mouse monoclonal anti-ERK2 antibody (1:500 dilution; catalog \#sc-1647, Santa Cruz Biotechnology) or rabbit polyclonal anti-phospho-p44/42 MAPK antibody (1:500 dilution; catalog \#4370S, RRID:AB_2315112, Cell Signaling Technology). A chemiluminescence detection system (PerkinElmer) was used for visualization.

Golgi-Cox staining. Golgi-Cox staining impregnation was performed using the FD Rapid GolgiStain Kit (FD Neuro Technologies) according to the manufacturer's instructions. Eight-week-old male mice were deeply anesthetized by intraperitoneal injection of the mixture of the aforementioned anesthetic agents, and their brains were removed and immersed in the impregnation solution composed of potassium dichromate, mercuric chloride, and potassium chromate. The brains were stored at room temperature for 2 weeks, transferred into the cryoprotectant solution, and kept for $3 \mathrm{~d}$ in the dark. The impregnated brains were then embedded in $3.5 \%$ agarose gel and cut with a vibratome (VT1000S; Leica Microsystems) at room temperature. Coronal sections of $100 \mu \mathrm{m}$ thickness were cut using a vibratome (VT1000S; Leica Biosystems), mounted on gelatin-coated glass slides (FD Neuro Technologies), and allowed to air dry at room temperature in the dark overnight. After drying, the sections were rinsed with pure water, reacted in the working solution, and dehydrated in a $50 \%, 75 \%, 95 \%$, and $100 \%$ graded ethanol series.

Morphological analysis. The total neurite length and neurite number per neuron were determined by manual tracing. Axonal and dendrite length, soma size, and number of primary neurites (that emerge from the soma and often split into more than one neurite segment) per neuron were determined for each individual cell using the BIO-REVO analysis platform (Keyence). Image analysis was performed in a blinded fashion using ImageJ software. Dendritic protrusions with widths larger than half their length were classified as mature spines.

Lentivirus injection into adult mouse brain. Seven-week-old male mice were deeply anesthetized by intraperitoneal injection of anesthetic agent mixture described above. A hole was opened in the scull above the hippocampus at -2.0 anterior and \pm 1.5 lateral from the bregma. A needle attached to a $25 \mu$ l Hamilton syringe was inserted to a depth of $1.7 \mathrm{~mm}$ into the CA1 hippocampus using stereotactic guidance, and $1.0 \mu \mathrm{l}$ of CMVVenus-miR132 or CMV-Venus lentivirus was injected into the brain over a period of $5 \mathrm{~min}$. Following inoculation, the needle was left in place for $5 \mathrm{~min}$ and then slowly withdrawn. The wound was sutured, and the mice were returned to their home cages. At $14 \mathrm{~d}$ following injection, mice were deeply anesthetized by intraperitoneal injection of anesthetic mixture and perfused through the left ventricle with $4 \%$ PFA. The brains were removed, postfixed overnight at $4^{\circ} \mathrm{C}$ in $4 \%$ PFA, and cryoprotected using $20 \%$ sucrose in PBS. The brain samples were cut at a thickness of 20 0.01 versus vehicle (Student's $t$ test).

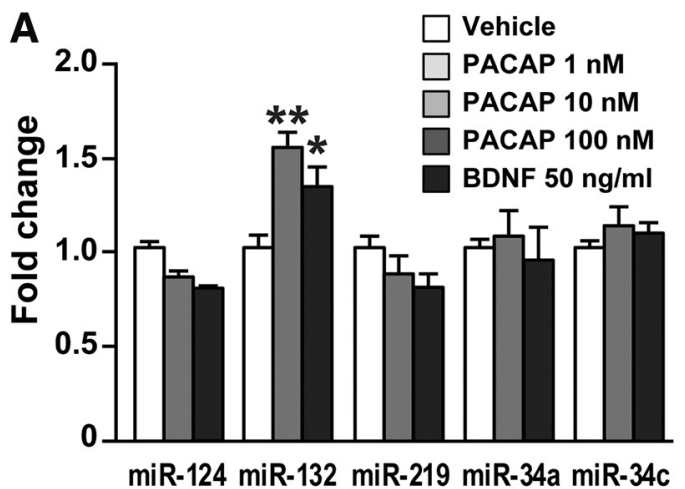

B miR-132

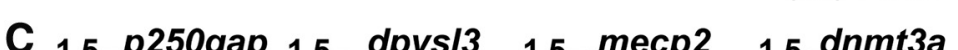

Figure 3. PACAP significantly increased the levels of miR-132 expression and decreased those of miR-132 targets in cultured hippocampal neurons. $\boldsymbol{A}, \boldsymbol{B}$, Expression revels of miRNAs in primary hippocampal neurons were determined by RT-PCR. Relative expression was normalized by snoRNA202. Primary hippocampal neurons were treated with $1 \mathrm{~nm}$ PACAP, $10 \mathrm{~nm}$ PACAP, $100 \mathrm{~nm}$ PACAP, or $50 \mathrm{ng} / \mathrm{ml}$ BDNF at DIV19 for $24 \mathrm{~h}$. Values indicate mean \pm SEM from four $(\boldsymbol{B})$ or five $(\boldsymbol{A})$ independent experiments. ${ }^{*} p<$ 0.05 versus vehicle (one-way ANOVA followed by Tukey-Kramer test). ${ }^{* *} p<0.01$ versus vehicle (one-way ANOVA followed by Tukey-Kramer test). C, The expression levels of miR-132 target genes (p250gap, ankrd11, fkbp2, dnmt3a, mecp2, dpys/3, gmfb, and sirt1) in primary hippocampal neurons were determined by qRT-PCR. Relative expression was normalized by gapdh. These samples were treated with $10 \mathrm{~nm}$ PACAP for $24 \mathrm{~h}$. Values indicate mean \pm SEM from five independent experiments. ${ }^{*} p<0.05$ versus vehicle (Student's $t$ test). ${ }^{* *} p<0.01$ versus vehicle (Student's $t$ test). D, The expression levels of p250GAP in primary hippocampal neurons were determined by Western blotting. The levels of p250GAP were normalized by those of total ERK1/2. These samples were treated with $10 \mathrm{~nm}$ PACAP for $48 \mathrm{~h}$. Values indicate mean \pm SEM from four independent experiments. ${ }^{* *} p<$

$\mu \mathrm{m}$ using a cryostat (CM1520, Leica Biosystems) and collected on Adhesive Silane-coated glass slides (Matsunami Glass).

Experimental design and statistical analysis. We tested the normality of data for parametric tests by using Kolmogorov-Smirnov test. The quality of variance assumption was verified by $F$ test. No randomization and blinding were performed for all experiments. No statistical tests were used for sample size calculation. The sample sizes were not predetermined, but determined based on our previous experiences and similar to those generally used in the field. The statistical analyses were performed using StatView software (version 5.0; SAS Institute). All experimental 
A
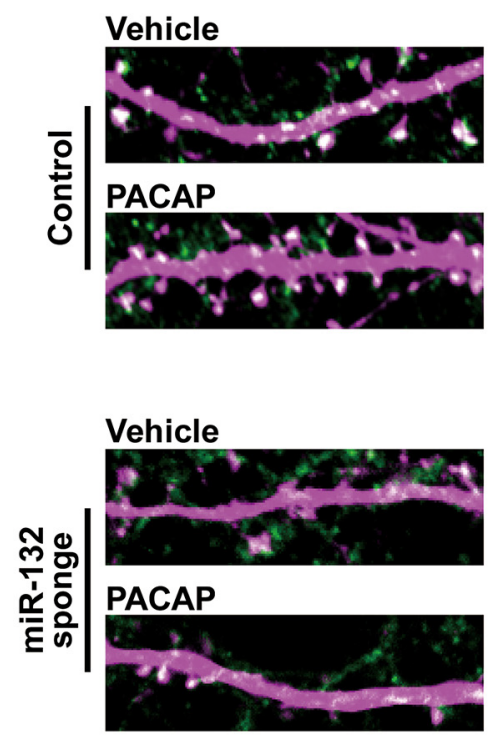

B
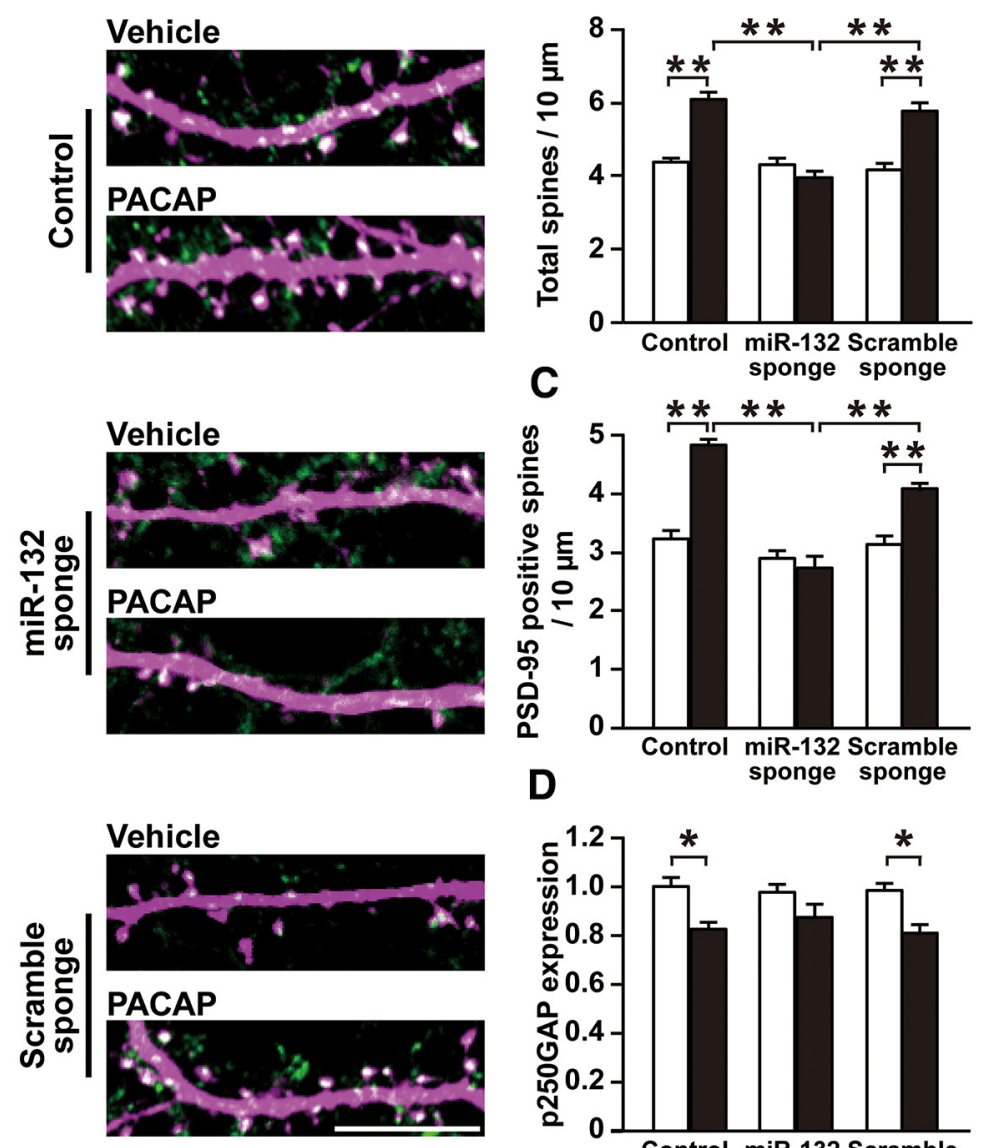

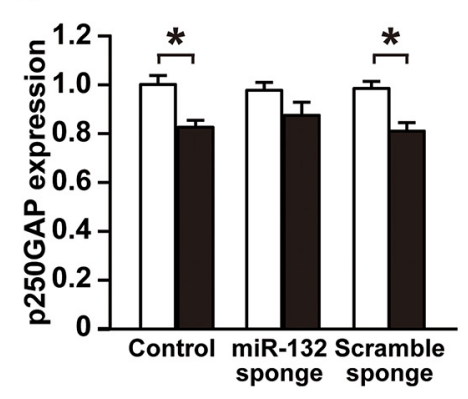

Figure 4. Viral expression of miR-132 sponge inhibited PACAP-induced miR-132 expression and decreased the levels of miR132 targets in the primary cultured hippocampal neurons. $\boldsymbol{A}$, Representative fluorescence images of the primary hippocampal neuronal dendrites at DIV21. Primary hippocampal neurons were transduced with miR-132 sponge or miR-132 scramble sponge lentivirus at DIV14 and treated with $10 \mathrm{~nm}$ PACAP at DIV19. The cells were fixed at DIV21 and immunostained with anti-DsRed (magenta) and anti-PSD95 (green) antibodies. Scale bar, $10 \mu \mathrm{m}$. B, C, Quantification of the number of total spines and PSD-95positive spines. Values indicate mean \pm SEM of 60 neurons from three independent experiments. $\boldsymbol{D}$, The expression level of p250gap in primary hippocampal neurons was determined by qRT-PCR. Relative expression was normalized to the levels of gapdh. These samples were treated with $10 \mathrm{~nm}$ at DIV19 for $24 \mathrm{~h} .{ }^{*} p<0.05$ versus vehicle (two-way ANOVA followed by Tukey-Kramer test). ${ }^{* *} p<0.01$ versus vehicle, control or scramble sponge (two-way ANOVA followed by Tukey-Kramer test).

data were analyzed using one-way or two-way ANOVA followed by the Tukey-Kramer or Student's $t$ test post hoc tests. The criterion for statistical significance was $p<0.05$.

\section{Results}

PACAP signaling modulates dendritic spine morphology and maturation

We used primary cultured hippocampal neurons to investigate the role of PACAP and BDNF in dendritic spine morphogenesis. Two days after the treatment with PACAP or BDNF (DIV19), we observed an increase in the total spine number. The increase observed following the treatment with 10 and 100 nM PACAP in primary cultured hippocampal neurons was comparable with that following BDNF treatment (one-way ANOVA: $F_{(4,295)}=$ $13.812, p<0.0001$; Fig. $1 A, B)$. PSD-95 is an essential component of postsynaptic density that promotes synaptic maturation and regulate synaptic functions (Xu, 2011; Coley and Gao, 2018). Quantitative analysis also showed an increase in the number of PSD-95-positive spines (magenta and green fluorescent merged spines) (one-way ANOVA: $F_{(4,295)}=10.855, p<0.0001$; Fig. $1 C$ ), but not that of PSD-95-negative spines at DIV21 (one-way
ANOVA: $F_{(4,295)}=1.824, p=0.124$; Fig. $1 D)$. To investigate whether PACAPincreased dendritic spines form morphological and functional synapses, we performed double-immunostaining for a presynaptic marker (synaptophysin) and a postsynaptic marker (PSD-95) in the primary cultured hippocampal neurons at DIV21 (Fig. $2 A-C$ ). We found that the treatment of primary cultured hippocampal neurons with 10 and 100 nM PACAP significantly increased the density of PSD95-positive spines that were apposed to synaptophysin-positive presynaptic terminals (one-way ANOVA: $F_{(3,236)}=$ 107.188, $p<0.0001$; Fig. $2 B, C)$. To functionally evaluate the PACAP-induced dendritic spines, we analyzed the cell surface protein expression levels by the surface biotinylation technique. We found that $10 \mathrm{nM}$ PACAP significantly increased the biotinylated NR1 $\left(t_{(8)}=-2.702, p=\right.$ $0.02)$ and NR2B $\left(t_{(8)}=-2.314, p=0.04\right)$ in the primary cultured hippocampal neurons at DIV14, suggesting that surface expression of the NMDA receptor is increased by PACAP (Fig. 2D,E). Then, we evaluated the function of the synaptic NMDA receptor by quantifying downstream ERK activation. Application of the potassium channel blocker 4-AP and the $\mathrm{GABA}_{\mathrm{A}}$ receptor blocker bicuculline is known to enhance synaptic transmission and increase the spontaneous firing rate through synaptic NMDA receptors (Hardingham et al., 2002; Nakazawa et al., 2008; Hoey et al., 2009). We stimulated the neurons with 4-AP and bicuculline for 5 min to activate synaptic NMDA receptors and observed that 4-AP and bicuculline significantly increased the ERK phosphorylation levels in the neurons treated with PACAP compared with vehicle-treated neurons (two-way ANOVA, PACAP effect, $F_{(1,18)}=5.775, p=0.0272,4$-AP and bicuculline effect, $F_{(2,18)}=$ 6.846, $p=0.0062$, interaction, $F_{(2,18)}=3.478, p=0.0528$; Fig. $2 F, G)$

PACAP increases the expression level of miR-132 in primary cultured hippocampal neurons

Some miRNAs are expressed at high levels in the brain and have been reported to correlate with abnormal brain function and dendritic spine morphology (Olde Loohuis et al., 2012; AksoyAksel et al., 2014; Follert et al., 2014). We thus examined whether or not PACAP signaling regulates miRNA expression in primary cultured hippocampal neurons. A mature miRNA-specific qRTPCR analysis was performed on major brain-specific miRNAs thought to be involved in synaptic plasticity, especially dendritic spine morphogenesis: miR-124,132, -219, -34a and -34c (Kocerha et al., 2009; Agostini et al., 2011; Soreq and Wolf, 2011). Among these miRNAs, only miR-132 expression was increased by PACAP or BDNF application for $24 \mathrm{~h}$ in the primary cultured hippocampal neurons (one-way ANOVA: $F_{(2,15)}=11.981, p=$ 
0.0008; Fig. 3A). The increase of miR-132 expression was observed at $1 \mathrm{nM}$ PACAP in contrast with the density of the dendritic spines in primary cultured hippocampal neurons (one-way ANOVA: $F_{(3,20)}=4.682, p=0.0123$; Fig. $\left.3 B\right)$. One of the miR-132 targets, p250GAP/ARHGAP32, which is a GTPase-activating protein for the Rho family of GTPases, plays an important role in NMDA receptormediated and activity-dependent dendritic spine plasticity (Nakazawa et al., 2003, 2008; Wayman et al., 2008; Dhar et al., 2014). We thus examined the effects of PACAP exposure on mRNA levels of the miR-132 targets in the primary cultured hippocampal neurons using qRT-PCR. A significant decrease was observed in the expression levels of p250GAP $\left(t_{(4)}=\right.$ 3.667, $p=0.01)$, dpysl3 $\left(t_{(4)}=3.563, p=\right.$ $0.01)$, and mecp $2\left(t_{(4)}=2.773, p=0.025\right)$ mRNAs following PACAP treatment (Fig. $3 C)$. In contrast, the mRNA levels of $d n m t 3 a$, ankrd11, fkbp2, bmfb, and sirt1 remained unchanged (Fig. 3C). Furthermore, PACAP induced a significant reduction in p250GAP protein levels $\left(t_{(3)}=\right.$ 5.712, $p=0.01$; Fig. 3D). The levels of p250GAP were normalized by those of total ERK1/2 as previously described (Wayman et al., 2008; Dhar et al., 2014).

PACAP regulates dendritic spine morphogenesis via miR-132

miR-132 overexpression transgenic mice via the CaMKII promoter show an increase in dendritic spine density of CA1 pyramidal neurons (Hansen et al., 2010). To examine whether PACAP-induced upregulation of the expression of miR-132 is involved in the induction of dendritic spine morphogenesis, we inhibited its expression by virally administering a "miR-132 sponge," which expressed the tdTomato reporter with a $3^{\prime}$ UTRcontaining multiple miR-132 binding sites (Ebert et al., 2007). The tdTomato/ miR-132 sponge was constructed and transduced using lentivirus in the primary cultured hippocampal neurons at DIV14. In primary cultured hippocampal neurons transduced with miRNA-132 sponge, but not in those transduced with scramble sponge, the PACAPinduced increase in the total spine and PSD-95-positive spine numbers at DIV21 was blunted (total spines; two-way ANOVA, sponge plasmid effect, $F_{(2,354)}=33.473, p<0.0001$; PACAP effect, $F_{(1,354)}=73.028, p<0.0001$; interaction, $F_{(2,354)}=23.785$, $p<0.0001$; PSD-95-positive spine number; two-way ANOVA, sponge plasmid effect, $F_{(2,354)}=33.120, p<0.0001$; PACAP effect, $F_{(1,354)}=41.916, p<0.0001$; interaction, $F_{(2,354)}=27.585$, $p<0.0001$; PSD-95-negative spine number; two-way ANOVA, sponge plasmid effect, $F_{(2,354)}=15.481, p<0.0001$; PACAP effect, $F_{(1,354)}=22.209, p<0.0001$; interaction, $F_{(2,354)}=2.325$,

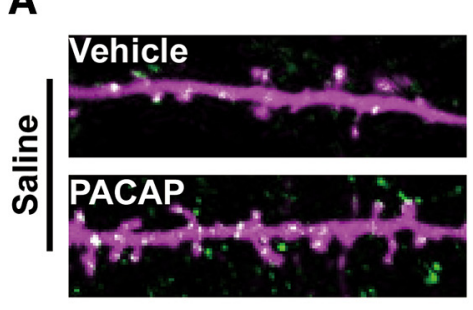

\section{B $\square$ Vehicle $\square$ PACAP}
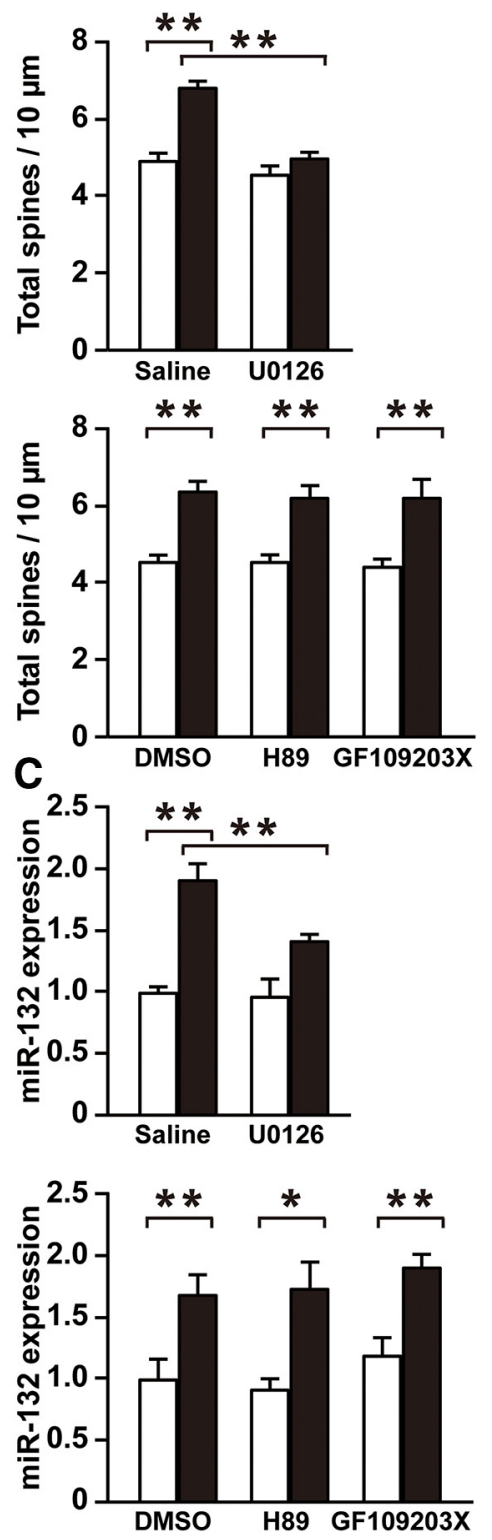

Figure 5. ERK signaling is involved in PACAP-induced expression of miR-132 and dendritic spine morphogenesis. A, Representative fluorescence images of primary hippocampal neuronal dendrites at DIV21. Primary hippocampal neurons were treated with $10 \mathrm{~nm}$ PACAP for $48 \mathrm{~h}$ at DIV19. The cells were pretreated with $2 \mu \mathrm{m}$ U0126, $1 \mu \mathrm{m}$ H89, or $1 \mu \mathrm{m}$ GF109203X for 30 min before PACAP treatment. At DIV21, the cells were fixed and immunostained with anti-DsRed (red) and anti-PSD95 (green) antibodies. Scale bar, $10 \mu \mathrm{m}$. B, Quantification of the number of total spines, PSD-95-positive spines, and PSD-95-negative spines. Values indicate mean \pm SEM of 60 neurons from three independent experiments. $C$, Total RNA, including miRNA, was extracted at DIV20, and the expression level of miR-132 was investigated by qRT-PCR. Values indicate mean \pm SEM from five independent experiments. ${ }^{*} p<$ 0.05 versus vehicle (two-way ANOVA followed by Tukey-Kramer test). ${ }^{* *} p<0.01$ versus vehicle or saline (two-way ANOVA followed by Tukey-Kramer test).

$p=0.0992$; Fig. 4A-C). Moreover, miRNA-132 sponge inhibited PACAP-induced reduction of p250gap expression (two-way ANOVA, transduced plasmid effect, $F_{(2,36)}=0.248, p=0.782$; treated effect, $F_{(1,36)}=25.948, p<0.0001$; interaction, $F_{(2,36)}=$ $0.425, p=0.657$; Fig. $4 D)$.

miRNA-132 is a cAMP-responsive element binding protein (CREB)-regulated miRNA. To investigate whether ERK-CREB signaling is involved in PACAP-induced dendritic spine morphogenesis, the cells were pretreated with U0126, a MEK inhibitor. U0126 inhibited PACAP-induced dendritic spine morphogenesis (two-way ANOVA, PACAP effect, $F_{(1,236)}=35.566, p<0.0001$, 
A

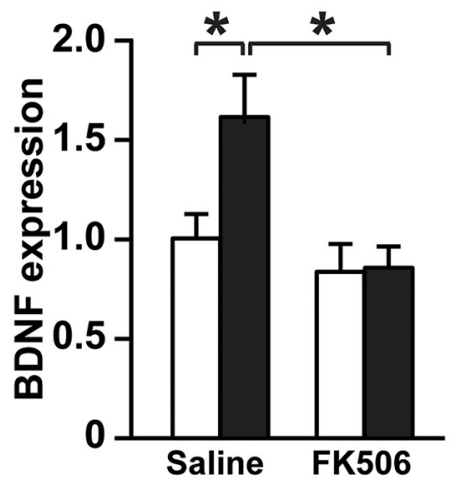

B

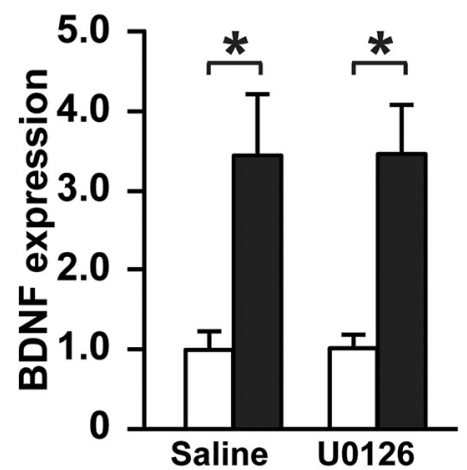

C

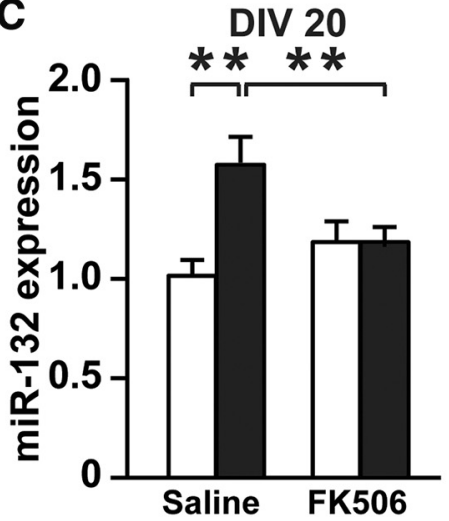

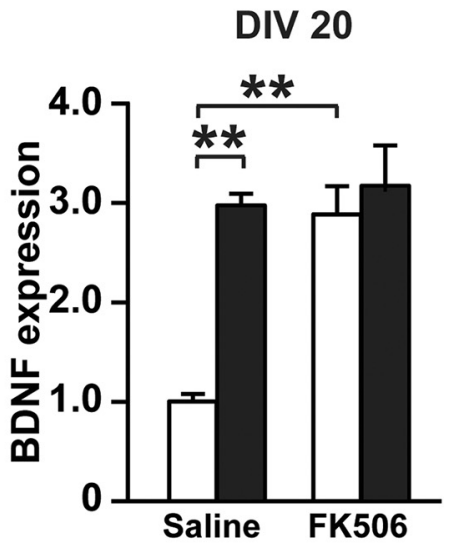

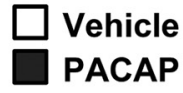

D

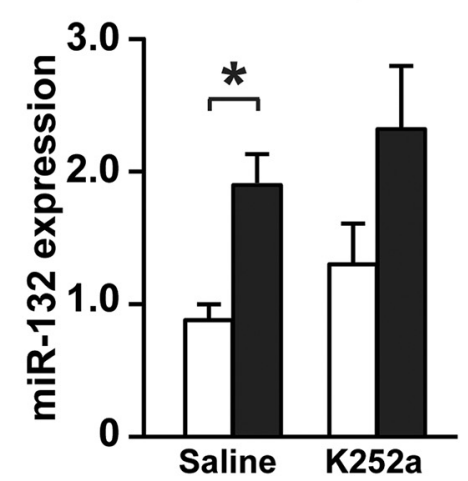

Figure 6. BDNF signaling is not involved in PACAP-induced expression of miR-132. Primary hippocampal cells were treated with $10 \mathrm{~nm}$ PACAP for $24 \mathrm{~h}$ at DIV4 or DIV19. The cells were pretreated with $5 \mu \mathrm{m}$ FK506 $(\boldsymbol{A}, \boldsymbol{C}), 2 \mu \mathrm{m}$ U0126 (B), or $10 \mathrm{~nm}$ k252a (D) at 30 min before PACAP treatment. Total RNA, including miRNA, was extracted at DIV 5 or DIV20, and the expression levels of $b d n f$ $(\boldsymbol{A}, \boldsymbol{B})$ or miR-132 $(\boldsymbol{C}, \boldsymbol{D})$ were investigated by qRT-PCR. Values indicate mean \pm SEM from three independent experiments. ${ }^{*} p<$ 0.05 versus vehicle or saline (two-way ANOVA followed by Tukey-Kramer test). ${ }^{* *} p<0.01$ versus vehicle or saline (two-way ANOVA followed by Tukey-Kramer test).

U0126 effect, $F_{(1,236)}=41.254, p<0.0001$; interaction, $F_{(1,236)}=$ 10.434, $p=0.0014$; Fig. 5A,B). Moreover, U0126 inhibited the PACAP-induced increase in the expression levels of miR-132 (twoway ANOVA, PACAP effect, $F_{(1,12)}=48.086, p<0.0001$; U0126 effect, $F_{(1,12)}=7.773, p=0.0164$; interaction, $F_{(1,12)}=5.986, p=$ 0.0308; Fig. 5C). In contrast, PACAP-induced dendritic spine morphogenesis and miR-132 expression were not affected by the protein kinase A inhibitor $\mathrm{H} 89$ or the protein kinase $\mathrm{C}$ inhibitor GF109203X (H89; two-way ANOVA, PACAP effect, $F_{(1,12)}=$ 23.242, $p=0.0004$; H89 effect, $F_{(1,12)}=0.037, p=0.850$; interaction, $F_{(1,12)}=0.370, p=0.554$; GF109203X, two-way ANOVA, PACAP effect, $F_{(1,12)}=15.239, p=0.0045$; GF109203X effect,

$F_{(1,12)}=3.538, p=0.097$; interaction,

$F_{(1,12)}=0.066, p=0.804$; Fig. $\left.5 A-C\right)$.

PACAP-induced BDNF does not increase the levels of miR-132 expression

A previous study has shown that PACAP induces $b d n f$ mRNA expression in primary cortical neurons (Fukuchi et al., 2015). Moreover, FK506, a specific inhibitor of calcineurin, blocked this PACAP-induced increase in $b d n f$ mRNA expression at DIV5 (Fukuchi et al., 2015). To examine whether BDNF might mediate the observed effects of PACAP on miR-132 expression and dendritic spine morphogenesis, hippocampal cells were pretreated with FK506, U0126, or K252a at DIV20. Although FK506 inhibited PACAP-induced miR-132 expression (twoway ANOVA, PACAP effect, $F_{(1,12)}=9.813$, $p=0.0087$; FK506 effect, $F_{(1,12)}=1.412$, $p=0.258$; interaction, $F_{(1,12)}=9.98, p=$ 0.0082; Fig. 6C), neither FK506 nor U0126 affected PACAP-induced $b d n f$ expression at DIV20 (FK506; two-way ANOVA, PACAP effect, $F_{(1,8)}=15.623, p=0.0042$; FK506 effect, $F_{(1,8)}=13.195, p=0.0067$; interaction, $F_{(1,8)}=8.657, p=0.0186$; U0126; two-way ANOVA, PACAP effect, $F_{(1,12)}=$ 25.559, $p=0.0003$; U0126 effect, $F_{(1,12)}=$ 0.001, $p=0.982$; interaction, $F_{(1,12)}<$ $0.0001, p=0.989$; Fig. $6 A, B)$. Moreover, $\mathrm{k} 252 \mathrm{a}$, a selective inhibitor of BDNF receptor TrkB, did not inhibit PACAP-induced miR-132 expression (two-way ANOVA, PACAP effect, $F_{(1,20)}=10.688, p=0.0038$; $\mathrm{k} 252 \mathrm{a}$ effect, $F_{(1,20)}=1.812, p=0.193$; interaction, $F_{(1,20)}<0.0001, p=0.999$; Fig. $6 D)$. These results indicate that PACAPinduced $b d n f$ expression is not involved in the increased miR-132 expression observed after PACAP treatment.

Hippocampal dendritic spine density and the level of miR-132 expression were decreased in primary cultured neurons from $P A C A P^{-1-}$ mice

We examined the role of PACAP in dendritic spine morphogenesis using a loss-of-function approach in primary cultured hippocampal neurons. We found that the number of PSD-95-positive spines that were apposed to synaptophysinpositive presynaptic terminals was significantly low in the primary cultured hippocampal neurons from $P A C A P^{-/-}$mice compared with WT mice (one-way ANOVA: $F_{(1,158)}=108.066$, $p<0.0001$; Fig. $7 A, B$ ). Figure $7 C$ shows that levels of miR-132 expression were significantly reduced in primary cultured hippocampal neurons from $P A C A P^{-/-}$mice compared with those from the control mice (one-way ANOVA: $F_{(1,16)}=6.827, p=$ 0.0188 ). Next, we examined the effect of miR-132 overexpression on dendritic spine formation in primary cultured hippocampal neurons. To do this, we generated the miR-132-Venus lentivirus 
and infected Venus control virus or miR-132-Venus virus into the primary neurons. $P A C A P^{-/-}$mice primary hippocampal neurons transduced with $\mathrm{Ve}$ nus control showed a decrease in the numbers of both total and PSD-95positive spines compared with that in WT mice, consistent with the lack of PACAP in $P A C A P^{-1-}$ mice, whereas the numbers of PSD-95-negative spines were not affected. In contrast, neurons transduced with miR-132-Venus showed increased numbers of the total and PSD-95-negative spines both in WT and $P A C A P^{-1-}$ mice primary hippocampal neurons (total spines; two-way ANOVA, miR-132 effect, $F_{(1,236)}=108.517, p<0.0001$; PACAP effect, $F_{(1,236)}=17.729, p<0.0001$; interaction, $F_{(1,236)}=8.477, p=0.0039$; PSD-95-negative spine number; two-way ANOVA, miR-132 effect, $F_{(1,236)}=25.724$, $p<0.0001$; PACAP effect, $F_{(1,236)}=$ $1.889, p=0.171$; interaction, $F_{(1,236)}=$ $0.799, p=0.372$; Fig. $7 B-D)$. The number of PSD-95-positive spines was increased only in the $P A C A P^{-/-}$mice primary hippocampal neurons (two-way ANOVA, miR-132 effect, $F_{(1,236)}=90.722, p<$ 0.0001 ; PACAP effect, $F_{(1,236)}=21.006$, $p<0.0001$; interaction, $F_{(1,236)}=26.731$, $p<0.0001$; Fig. $7 B, D)$. These data indicate that PACAP regulates dendritic spine density and morphology and the overexpression of miR-132 increases the size and density of dendritic spines in the $P A C A P^{-/-}$mice primary neurons.

miR-132 overexpression increased the number of total spines in the hippocampal CA1 region of PACAPdeficient mice

To investigate morphological changes of dendritic spines in the hippocampal pyramidal neurons of $P A C A P^{-/-}$mice, we performed Golgi staining on coronal sections of the brains isolated from 8 - to 9-week-old WT and PACAP ${ }^{-1-}$ mice. Golgi impregnation demonstrated that dendritic spine density of CA1 pyramidal neurons was significantly decreased in the hippocampus of $P A C A P^{-/-}$mice, compared with that in WT mice $\left(t_{(54)}=2.246, p=0.029\right.$; Fig. $\left.8 A, B\right)$. Furthermore, to evaluate dendritic spine morphology, we measured the dendritic spine length and dendritic spine head diameter. The dendritic spine length in $P A C A P^{-/-}$mice was slightly, but significantly, shorter than that in WT mice $\left(t_{(54)}=2.007, p=0.049\right.$; Fig. $\left.8 C, E\right)$. The dendritic spine head diameter of $P A C A P^{-/-}$mice was also larger than that in WT $\left(t_{(54)}=-2.183, p=0.033\right.$; Fig. $\left.8 D, F\right)$. These results indicate that $\mathrm{PACAP}$ regulates dendritic spine density and morphology in the CA1 pyramidal neurons in vivo.

Next, to investigate whether synaptic defects observed in $P A C A P^{-1-}$ mice could be directly rescued by miR-132 overexpression, we performed a microinjection of miR-132-Venus into the mouse bilateral CA1 region of the hippocampus in the
B

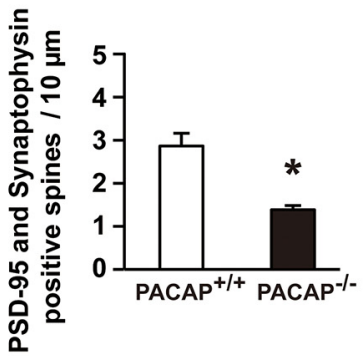

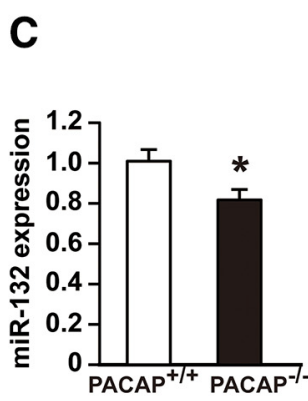
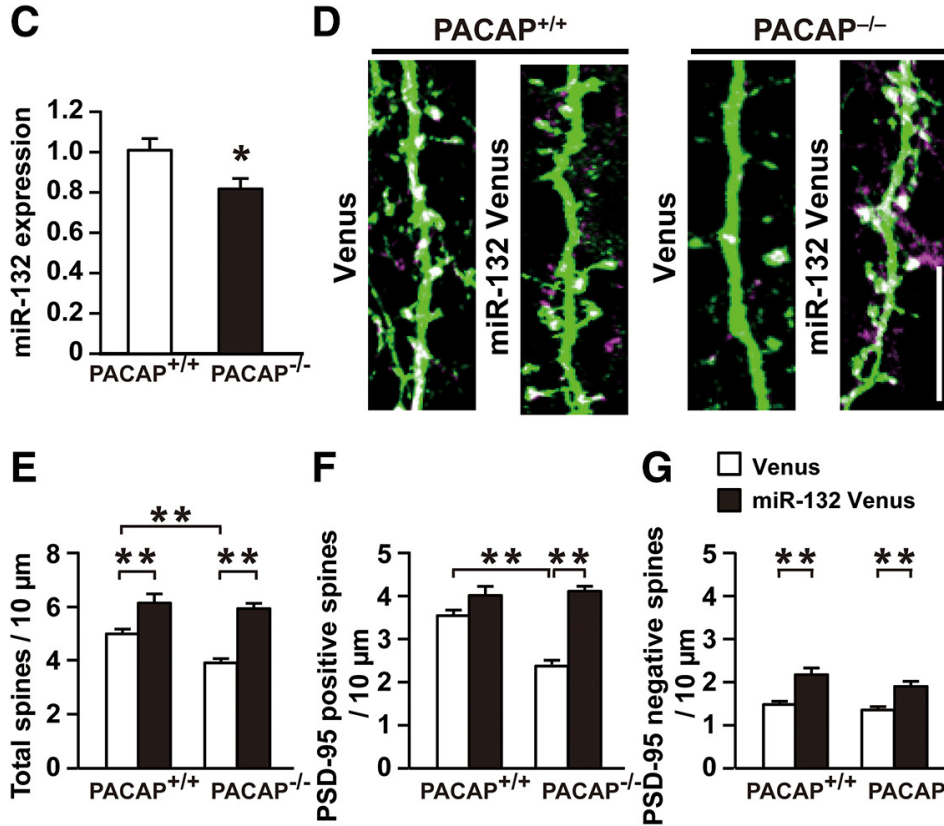

F
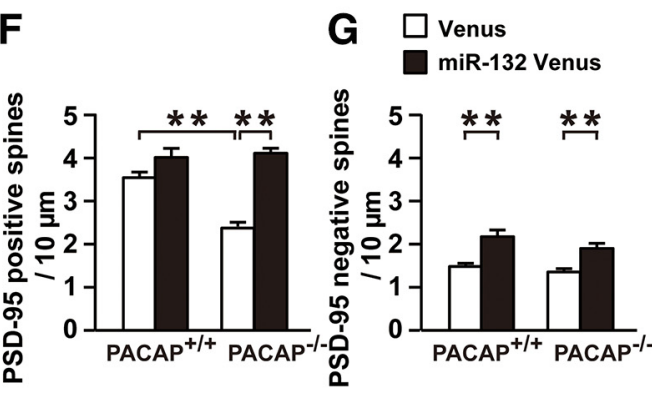

Figure 7. Viral expression of miR-132 increased dendritic spine density in the primary hippocampal neurons from $P A C A P^{-/-}$ mice. $A$, Representative fluorescence images of the primary hippocampal neuronal dendrites at DIV21. The cells were fixed at DIV21 and immunostained using anti-synaptophysin (magenta) and anti-PSD95 (green) antibodies. Scale bar, $10 \mu \mathrm{m}$. $\boldsymbol{B}$, Quantification mean \pm SEM on 80 neurons from four independent experiments. ${ }^{*} p<0.05$ versus vehicle (one-way ANOVA followed by ments. ${ }^{*} p<0.05$ versus WT (one-way ANOVA followed by Tukey-kramer test). D Representative fluorescence images of primary positive spines $(\boldsymbol{F})$, and -negative spines $(\boldsymbol{G})$. Values indicate mean \pm SEM of 60 neurons from three independent experiments. ${ }^{* *} p<0.01$ versus Venus or WT (two-way ANOVA followed by Tukey-Kramer test).

PACAP ${ }^{-/-}$mice (Fig. 9A). Two weeks after injection of miR-132Venus or control, we examined the gene expression levels of miR132, miR-124, and the Venus reporter. In Figure 9B, the expression of venus was detected in the CA1 region of all injected mice, and the expression levels of miR-132 were increased $\sim 3$ times in the group injected with miR-132 (two-way ANOVA, gene effect, $F_{(1,24)}=0.205, p=0.655$; miR-132 effect, $F_{(1,24)}=$ $17.628, p=0.0003$; interaction, $\left.F_{(1,24)}=0.952, p=0.339\right)$. On the contrary, the expression levels of miR-124 remained unchanged (two-way ANOVA, gene effect, $F_{(1,24)}=1.591, p=$ 0.219 ; miR-132 effect, $F_{(1,24)}=0.015, p=0.902$; interaction, $\left.F_{(1,24)}=0.049, p=0.827\right)$. We found that miR-132 overexpression in the hippocampal CA1 region in $P A C A P^{-/-}$mice significantly increased the number of dendritic spines (Fig. 9C). In contrast, the injection of miR-132-Venus into the hippocampal $\mathrm{CA} 1$ region of WT mice resulted in a decrease in the number of 
A
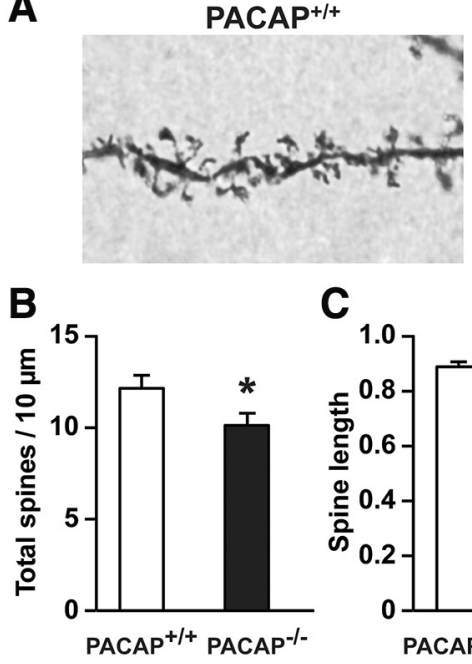

C

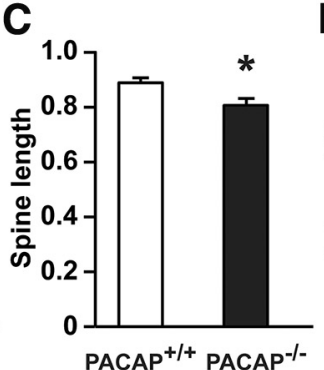

D
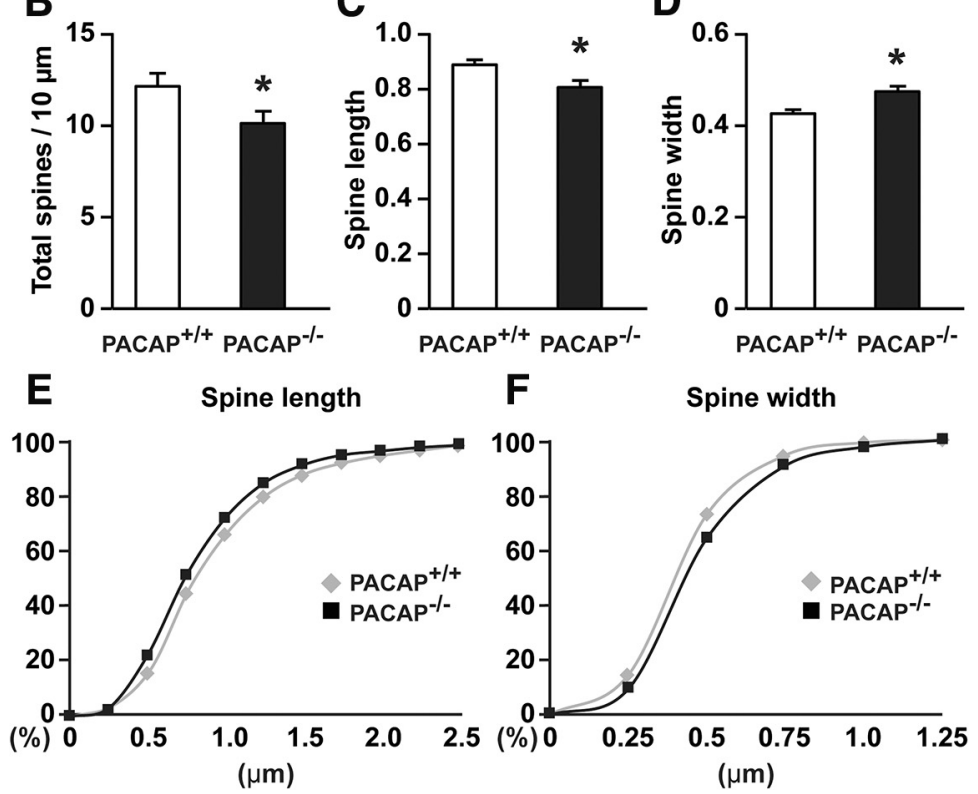

$F$

Spine width

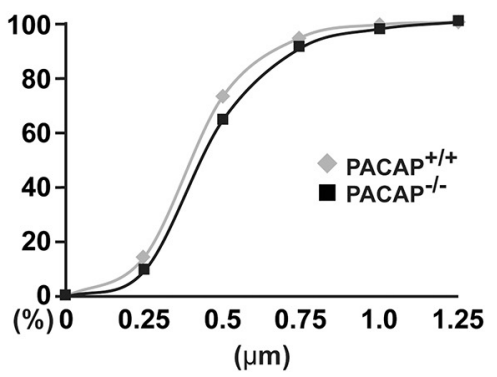

Figure 8. Morphological analysis of dendritic spines on hippocampal pyramidal neurons in $P A C A P^{-/-}$mice using Golgi staining. $A$, Representative images of Golgi-stained pyramidal neurons in the hippocampal CA1 region of WT (left) or $P A C A P^{-1-}$ (right) mice. Scale bar, $10 \mu \mathrm{m}$. B, Quantification of the number of total spines. Values indicate mean \pm SEM of 30 neurons from three independent experiments. $\boldsymbol{C}-\boldsymbol{F}$, The mean spine length $(\boldsymbol{C})$ or spine head width $(\boldsymbol{D})$ from WT and PACAP ${ }^{-1-}$ mice, and the cumulative frequency plot of each spine length $(\boldsymbol{E})$ or width $(\boldsymbol{F})$ from WT and $P A C A P^{-1-}$ mice. The analysis was performed by measuring the spines ( $n=675$ spines/WT and 602 spines/PACAP ${ }^{-1-}$ mice). Values indicate mean \pm SEM of 4 animals per genotype. ${ }^{*} p<0.05$ versus WT (Student's $t$ test).

Venus-positive dendritic spines compared with the group that received control Venus injection (two-way ANOVA, gene effect, $F_{(1,12)}=0.378, p=0.550$; miR-132 effect, $F_{(1,12)}=20.833, p=$ 0.0006 ; interaction, $\left.F_{(1,12)}=44.307, p<0.0001\right)$.

\section{Discussion}

In this study, we provided new evidence supporting a critical role of PACAP signaling in dendritic spine maturation and morphology. PACAP changed the size and density of the hippocampal dendritic spines in vivo and in vitro. Interestingly, PACAP increased surface NMDA receptor and upregulated the NMDA receptor-mediated signaling in the primary hippocampal cultured neurons (Fig. 2), suggesting that PACAP increased functional synapses. We also found, to our knowledge for the first time, that PACAP was involved in the regulation of miRNA expression and that, specifically, miR-132 mediated the effect of PACAP on the spine maturation (Fig. 3).

We found that 1 nM PACAP increased the miR-132 expression level to the same level as 10 or $100 \mathrm{~nm}$ PACAP in the primary cultured hippocampal neurons (Fig. 3B). Considering that $1 \mathrm{nM}$ PACAP did not increase the number of dendritic spines (Figs. 1, 2 ), this result suggests that not only miR-132 but also other effectors are involved in the downstream signaling in the 10 and 100 nM PACAP-induced dendritic spine formation and maturation. Although previous studies have found that $10 \mathrm{~nm}$ PACAP, but not $1 \mathrm{~nm}$ PACAP, induces the intracellular calcium release and p38 kinase activation (Kopp et al., 1999; Sakai et al., 2002), the specific 10 and $100 \mathrm{~nm}$ PACAP-inducing signaling pathways required for dendritic spine formation are currently unclear. Alternatively or in addition, different experimental conditions on the stimulation period, cell density, and so on may reconcile the seemingly inconsistent results between the expression of miR-132 and dendritic spine formation. Future studies on the functional relationships between miR-132- and other PACAP-mediated signaling pathways unravel the precise role of PACAP in the dendritic spine formation and maturation.

We found that overexpression of miR132 rescued impaired dendritic spine density of $P A C A P^{-/-}$mice in vivo and in vitro (Figs. 7, 9), suggesting that miR-132 is an important factor that mediates the effect of PACAP on the dendritic spine maturation. However, while miR-132 increased both PSD-95-positive and -negative spines, we confirmed that PACAP increased only PSD-95-positive functional dendritic spines (Figs. $1 C, D, 7 F, G$ ). Considering that, in addition to PACAP, several neurotrophic signals such as BDNF, leptin signal, and neuronal activity are known to affect miR-132 expression and the dendritic spine density in the hippocampus (Ji et al., 2005; Kawashima et al., 2010; Nudelman et al., 2010; Dhar et al., 2014; Kellner et al., 2014), PACAPand miR-132-mediated dendritic spineinducing signaling pathways may only be partially overlapping. Alternatively, PACAP may increase both PSD-95-positive and -negative spines via miR-132, immediately followed by the maturation of dendritic spines via other downstream effectors.

The reason that overexpression of miR-132 decreased the number of dendritic spines in WT mice is currently unclear (Fig. 9C). Previous studies have found that both overexpression and loss of function of one of miR-132 major targets, MeCP2, result in similar decrease in the dendritic spine density (Xu et al., 2014), suggesting that the proper expression of miR-132 as well as $\mathrm{MeCP} 2$ is important for dendritic spine morphogenesis and that the excess miR-132 overexpression decreases the dendritic spine density in WT mice in which miR-132 is adequately expressed. Alternatively or in addition, miR-132 may play broader roles in the regulation of dendritic spines than PACAP does; miR-132 overexpression may activate several PACAP-independent signaling pathways that contribute to decrease dendritic spine density. It will be important to precisely examine the dose-dependent effect of miR-132 overexpression on the dendritic spine density for clarifying the role of miR-132 in PACAP-mediated signaling pathways.

PACAP is known to induce upregulation of BDNF (Yaka et al., 2003). Because BDNF elicits miR-132 expression and dendritic spine maturation (Ji et al., 2005; Kawashima et al., 2010; Kellner 
et al., 2014), we wondered whether PACAP-induced increases in BDNF could underlie the miR-132 upregulation we observed; however, our results suggest that PACAP-induced miR-132 expression is not mediated by BDNF signaling (Fig. 6). It is well known that BDNF activates various intracellular signaling pathways, including MAPK/ERK, phospholipase C and phosphoinositide 3-kinase (Huang and Reichardt, 2003). In addition to the regulation of dendritic spine morphogenesis, BDNF also regulates local mRNA translation and trafficking via phosphoinositide 3-kinase signaling and phospholipase $\mathrm{C}$ signaling in neurons (Schratt et al., 2004; Yoshii and Constantine-Paton, 2010). It is thus a possible scenario that PACAP-induced BDNF may activate phosphoinositide 3-kinase signaling and phospholipase $\mathrm{C}$ signaling to regulate local mRNA translation and trafficking, but not ERK-CREB signaling to regulate dendritic spine morphogenesis by increasing miR-132 expression. Alternatively, PACAP-induced $b d n f$ expression level may not have been enough for inducing miR-132 upregulation. Future experiments will be needed to reveal the molecular mechanisms of the various function of PACAP signaling in the CNS.

Although the high affinity PACAP receptor, PAC1, appears to be robustly expressed in the dentate gyrus (Hashimoto et al., 1996), we found dendritic spine morphological abnormalities in CA1 pyramidal neurons but not dentate gyrus pyramidal neurons in $P A C A P^{-/-}$mice (Fig. 8 ; and data not shown). This discrepancy may be explained by differences in the expression of miR-132. Indeed, miR-132 expression is higher in the CA1 region than in the molecular layer of the dentate gyrus in the hippocampus (Hansen et al., 2013). In support of this, miR-132-related signal, BDNF stimulation, or constitutive activated CREB mutant mice was reported to be accompanied by changes in the dendritic spine density in the CA1 region (Alonso et al., 2004; Serita et al., 2017).

In contrast to primary cultured neurons, we found that the level of miR-132 was marginally, but not significantly, low in the hippocampal CA1 region of $P A C A P^{-1-}$ mice (Fig. $9 B$ ). Although there is an undeniable possibility that the effect of PACAP deficiency on the level of miR-132 is specific for primary cultured neurons, we assume that the seemingly inconsistent results may be attributable to the considerable expression of miR-132 in glial cells and endothelial cells as well as in the neurons. Previous studies have found that the expression of miR-132 is differentially regulated by several growth factors in neurons and glial cells (Anand et al., 2010; Numakawa et al., 2011), implying that the expression level of miR-132 is not regulated by PACAP in glial cells and endothelial cells. Accordingly, the expression level of miR-132 may be unchanged in glial cells and endothelial cells of

B
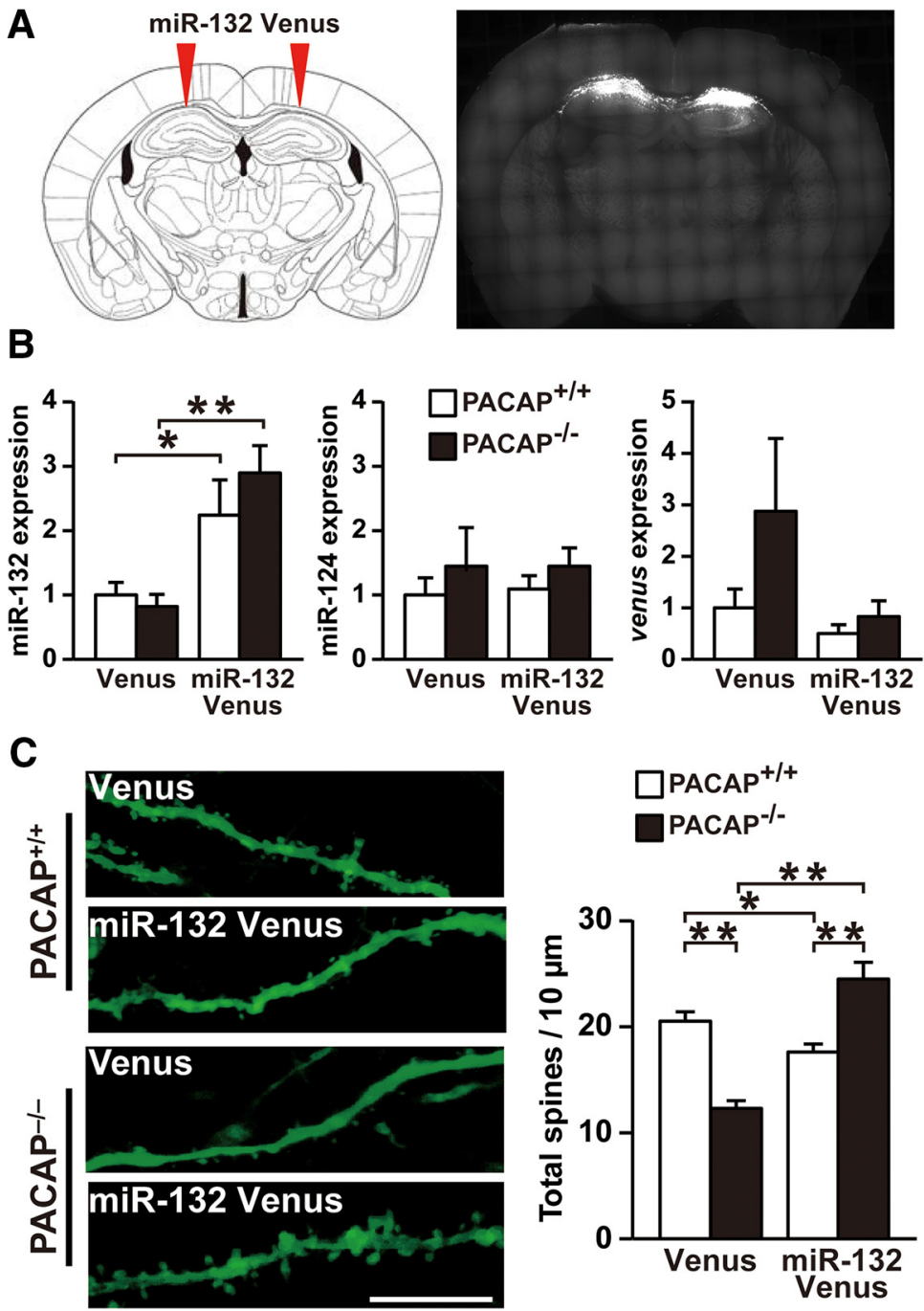

Figure 9. Microinjection of miR-132-Venus into the mouse CA1 area in the WT and PACAP ${ }^{-/-}$mice. A, Schematic drawing and representative fluorescence images of bilateral lentivirus transduction in the hippocampal CA1 region of the brain slice showing the location of the injection. $\boldsymbol{B}$, The expression levels of miRNAs or related mRNAs in the hippocampal CA1 region were determined by neurons from four or five mice. ${ }^{*} p<0.05$ versus Venus (two-way ANOVA followed by Tukey-kramer test). ${ }^{* *} p<0.01$ versus Venus or WT (two-way ANOVA followed by Tukey-Kramer test).

PACAP ${ }^{-/-}$mice, which mask the decreased expression of miR132 in the neurons in vivo. In contrast to in vivo, given the contamination of glial and other cells is minimized in our cultured neurons, the decreased miR-132 expression can be detected in the primary hippocampal cultured neurons. Alternatively, given that PACAP is absent throughout whole developmental and adult stages in $P A C A P^{-/-}$mice, unidentified in vivo-specific compensatory mechanisms may incidentally increase miR-132 expression in $P A C A P^{-1-}$ mice. To address these possibilities, further precise cell type-specific analysis of the miR-132 expression patterns at the single-cell level will be important.

Recent studies have indicated that PSD-95 dysfunction is associated with cognitive and learning deficits in patients with schizophrenia (Fromer et al., 2014; Purcell et al., 2014). miR-132 is also suggested to be involved in the pathogenesis of schizophrenia, autism spectrum disorder, Alzheimer's disease, and Parkinson's disease (Miller et al., 2012; Hara et al., 2017; Qian et al., 
2017). Together, our data raise the hypothesis that dysregulation of PACAP-miR-132 signaling may be involved, at least partially, in the molecular pathogenesis of these neuropsychiatric disorders by modulating dendritic spine formation and maturation.

In conclusion, our results indicate that PACAP-miR-132 signaling axis plays a critical role in dendritic spine morphogenesis in the CA1 hippocampal region of mice. Dysfunction of PACAP signaling may, thus, contribute to the pathogenesis of neuropsychiatric disorders by inducing dendritic spine abnormalities via miR-132 dysregulation. Our findings contribute to a better understanding of the molecular mechanisms underlying some neuropsychiatric disorders, such as schizophrenia. However, further studies will be needed to examine whether miRNA-132 or PACAP-targeted therapies may constitute a new glimpse of hope for the treatment of these disorders.

\section{References}

Ago Y, Hiramatsu N, Ishihama T, Hazama K, Hayata-Takano A, Shibasaki Y, Shintani N, Hashimoto H, Kawasaki T, Onoe H, Chaki S, Nakazato A, Baba A, Takuma K, Matsuda T (2013) The selective metabotropic glutamate $2 / 3$ receptor agonist MGS0028 reverses psychomotor abnormalities and recognition memory deficits in mice lacking the pituitary adenylate cyclase-activating polypeptide. Behav Pharmacol 24:74-77.

Agostini M, Tucci P, Steinert JR, Shalom-Feuerstein R, Rouleau M, Aberdam D, Forsythe ID, Young KW, Ventura A, Concepcion CP, Han YC, Candi E, Knight RA, Mak TW, Melino G (2011) microRNA-34a regulates neurite outgrowth, spinal morphology, and function. Proc Natl Acad Sci U S A 108:21099-21104.

Aksoy-Aksel A, Zampa F, Schratt G (2014) MicroRNAs and synaptic plasticity-a mutual relationship. Philos Trans R Soc Lond B Biol Sci 369: 20130515.

Alonso M, Medina JH, Pozzo-Miller L (2004) ERK1/2 activation is necessary for BDNF to increase dendritic spine density in hippocampal CA1 pyramidal neurons. Learn Mem 11:172-178.

Anand S, Majeti BK, Acevedo LM, Murphy EA, Mukthavaram R, Scheppke L, Huang M, Shields DJ, Lindquist JN, Lapinski PE, King PD, Weis SM, Cheresh DA (2010) MicroRNA-132-mediated loss of p120RasGAP activates the endothelium to facilitate pathological angiogenesis. Nat Med 16:909-914.

Bailey CH, Kandel ER, Harris KM (2015) Structural components of synaptic plasticity and memory consolidation. Cold Spring Harb Perspect Biol 7:a021758.

Beveridge NJ, Cairns MJ (2012) MicroRNA dysregulation in schizophrenia. Neurobiol Dis 46:263-271.

Coley AA, Gao WJ (2018) PSD95: a synaptic protein implicated in schizophrenia or autism? Prog Neuropsychopharmacol Biol Psychiatry 82:187194.

Dhar M, Zhu M, Impey S, Lambert TJ, Bland T, Karatsoreos IN, Nakazawa T, Appleyard SM, Wayman GA (2014) Leptin induces hippocampal synaptogenesis via CREB-regulated microRNA-132 suppression of p250GAP. Mol Endocrinol 28:1073-1087.

Ebert MS, Neilson JR, Sharp PA (2007) MicroRNA sponges: competitive inhibitors of small RNAs in mammalian cells. Nat Methods 4:721-726.

Edbauer D, Neilson JR, Foster KA, Wang CF, Seeburg DP, Batterton MN, Tada T, Dolan BM, Sharp PA, Sheng M (2010) Regulation of synaptic structure and function by FMRP-associated microRNAs miR-125b and miR-132. Neuron 65:373-384.

Fénelon K, Xu B, Lai CS, Mukai J, Markx S, Stark KL, Hsu PK, Gan WB, Fischbach GD, MacDermott AB, Karayiorgou M, Gogos JA (2013) The pattern of cortical dysfunction in a mouse model of a schizophreniarelated microdeletion. J Neurosci 33:14825-14839.

Follert P, Cremer H, Béclin C (2014) MicroRNAs in brain development and function: a matter of flexibility and stability. Front Mol Neurosci 7:5.

Fromer M, Pocklington AJ, Kavanagh DH, Williams HJ, Dwyer S, Gormley P, Georgieva L, Rees E, Palta P, Ruderfer DM, Carrera N, Humphreys I, Johnson JS, Roussos P, Barker DD, Banks E, Milanova V, Grant SG, Hannon E, Rose SA, et al. (2014) De novo mutations in schizophrenia implicate synaptic networks. Nature 506:179-184.

Fukuchi M, Tabuchi A, Kuwana Y, Watanabe S, Inoue M, Takasaki I, Izumi $\mathrm{H}$, Tanaka A, Inoue R, Mori H, Komatsu H, Takemori H, Okuno H, Bito
H, Tsuda M (2015) Neuromodulatory effect of G $\alpha$ s- or G $\alpha$-coupled G-protein-coupled receptor on NMDA receptor selectively activates the NMDA receptor/ $\mathrm{Ca}^{2+} /$ calcineurin/cAMP response element-binding protein-regulated transcriptional coactivator 1 pathway to effectively induce brain-derived neurotrophic factor expression in neurons. J Neurosci 35:5606-5624.

Glausier JR, Lewis DA (2013) Dendritic spine pathology in schizophrenia. Neuroscience 251:90-107.

Hansen KF, Sakamoto K, Wayman GA, Impey S, Obrietan K (2010) Transgenic miR132 alters neuronal spine density and impairs novel object recognition memory. PLoS One 5:e15497.

Hansen KF, Karelina K, Sakamoto K, Wayman GA, Impey S, Obrietan K (2013) miRNA-132: a dynamic regulator of cognitive capacity. Brain Struct Funct 218:817-831.

Hara Y, Ago Y, Takano E, Hasebe S, Nakazawa T, Hashimoto H, Matsuda T, Takuma K (2017) Prenatal exposure to valproic acid increases miR-132 levels in the mouse embryonic brain. Mol Autism 8:33.

Hardingham GE, Fukunaga Y, Bading H (2002) Extrasynaptic NMDARs oppose synaptic NMDARs by triggering CREB shut-off and cell death pathways. Nat Neurosci 5:405-414.

Hashimoto H, Nogi H, Mori K, Ohishi H, Shigemoto R, Yamamoto K, Matsuda T, Mizuno N, Nagata S, Baba A (1996) Distribution of the mRNA for a pituitary adenylate cyclase-activating polypeptide receptor in the rat brain: an in situ hybridization study. J Comp Neurol 371:567-577.

Hashimoto H, Shintani N, Tanaka K, Mori W, Hirose M, Matsuda T, Sakaue M, Miyazaki J, Niwa H, Tashiro F, Yamamoto K, Koga K, Tomimoto S, Kunugi A, Suetake S, Baba A (2001) Altered psychomotor behaviors in mice lacking pituitary adenylate cyclase-activating polypeptide (PACAP). Proc Natl Acad Sci U S A 98:13355-13360.

Hashimoto H, Hashimoto R, Shintani N, Tanaka K, Yamamoto A, Hatanaka M, Guo X, Morita Y, Tanida M, Nagai K, Takeda M, Baba A (2009) Depression-like behavior in the forced swimming test in PACAPdeficient mice: amelioration by the atypical antipsychotic risperidone. J Neurochem 110:595-602

Hashimoto R, Hashimoto H, Shintani N, Chiba S, Hattori S, Okada T, Nakajima M, Tanaka K, Kawagishi N, Nemoto K, Mori T, Ohnishi T, Noguchi H, Hori H, Suzuki T, Iwata N, Ozaki N, Nakabayashi T, Saitoh O, Kosuga A, et al. (2007) Pituitary adenylate cyclase-activating polypeptide is associated with schizophrenia. Mol Psychiatry 12:1026-1032.

Hoey SE, Williams RJ, Perkinton MS (2009) Synaptic NMDA receptor activation stimulates secretase amyloid precursor protein processing and inhibits amyloid-beta production. J Neurosci 29:4442-4460.

Huang EJ, Reichardt LF (2003) Trk receptors: roles in neuronal signal transduction. Annu Rev Biochem 72:609-642.

Ji Y, Pang PT, Feng L, Lu B (2005) Cyclic AMP controls BDNF-induced TrkB phosphorylation and dendritic spine formation in mature hippocampal neurons. Nat Neurosci 8:164-172.

Kaufmann WE, Moser HW (2000) Dendritic anomalies in disorders associated with mental retardation. Cereb Cortex 10:981-991.

Kawashima H, Numakawa T, Kumamaru E, Adachi N, Mizuno H, Ninomiya M, Kunugi H, Hashido K (2010) Glucocorticoid attenuates brainderived neurotrophic factor-dependent upregulation of glutamate receptors via the suppression of microRNA-132 expression. Neuroscience 165: 1301-1311.

Kellner Y, Gödecke N, Dierkes T, Thieme N, Zagrebelsky M, Korte M (2014) The BDNF effects on dendritic spines of mature hippocampal neurons depend on neuronal activity. Front Synaptic Neurosci 6:5.

Kocerha JF, Lopez-Toledano MA, Huang J, Ramsey AJ, Caron MG, Sales N, Willoughby D, Elmen J, Hansen HF, Orum H, Kauppinen S, Kenny PJ, Wahlestedt C (2009) MicroRNA-219 modulates NMDA receptormediated neurobehavioral dysfunction. Proc Natl Acad Sci U S A 106: 3507-3512.

Kopp MD, Schomerus C, Dehghani F, Korf HW, Meissl H (1999) Pituitary adenylate cyclase-activating polypeptide and melatonin in the suprachiasmatic nucleus: effects on the calcium signal transduction cascade. J Neurosci 19:206-219.

Lai KO, Ip NY (2013) Structural plasticity of dendritic spines: the underlying mechanisms and its dysregulation in brain disorders. Biochim Biophys Acta 1832:2257-2263.

Mabuchi T, Shintani N, Matsumura S, Okuda-Ashitaka E, Hashimoto H, Muratani T, Minami T, Baba A, Ito S (2004) Pituitary adenylate cyclase- 
activating polypeptide is required for the development of spinal sensitization and induction of neuropathic pain. J Neurosci 24:7283-7291.

Miller BH, Zeier Z, Xi L, Lanz TA, Deng S, Strathmann J, Willoughby D, Kenny PJ, Elsworth JD, Lawrence MS, Roth RH, Edbauer D, Kleiman RJ, Wahlestedt C (2012) MicroRNA-132 dysregulation in schizophrenia has implications for both neurodevelopment and adult brain function. Proc Natl Acad Sci U S A 109:3125-3130.

Moyer CE, Shelton MA, Sweet RA (2015) Dendritic spine alterations in schizophrenia. Neurosci Lett 601:46-53.

Nakazawa T, Watabe AM, Tezuka T, Yoshida Y, Yokoyama K, Umemori H, Inoue A, Okabe S, Manabe T, Yamamoto T (2003) p250GAP, a novel brain-enriched GTPase-activating protein for rho family GTPases, is involved in the N-methyl-D-aspartate receptor signaling. Mol Biol Cell 14:2921-2934.

Nakazawa T, Kuriu T, Tezuka T, Umemori H, Okabe S, Yamamoto T (2008) Regulation of dendritic spine morphology by an NMDA receptorassociated rho GTPase-activating protein, p250GAP. J Neurochem 105:1384-1393.

Nudelman AS, DiRocco DP, Lambert TJ, Garelick MG, Le J, Nathanson NM, Storm DR (2010) Neuronal activity rapidly induces transcription of the CREB-regulated microRNA-132, in vivo. Hippocampus 20:492-498.

Numakawa T, Yamamoto N, Chiba S, Richards M, Ooshima Y, Kishi S, Hashido K, Adachi N, Kunugi H (2011) Growth factors stimulate expression of neuronal and glial miR-132. Neurosci Lett 505:242-247.

Ogata K, Shintani N, Hayata-Takano A, Kamo T, Higashi S, Seiriki K, Momosaki H, Vaudry D, Vaudry H, Galas L, Kasai A, Nagayasu K, Nakazawa T, Hashimoto R, Ago Y, Matsuda T, Baba A, Hashimoto H (2015) PACAP enhances axon outgrowth in cultured hippocampal neurons to a comparable extent as BDNF. PLoS One 10:e0120526.

Olde Loohuis NF, Kos A, Martens GJ, Van Bokhoven H, Nadif Kasri N, Aschrafi A (2012) MicroRNA networks direct neuronal development and plasticity. Cell Mol Life Sci 69:89-102.

Penzes P, Cahill ME, Jones KA, VanLeeuwen JE, Woolfrey KM (2011) Dendritic spine pathology in neuropsychiatric disorders. Nat Neurosci 14:285-293.

Purcell SM, Moran JL, Fromer M, Ruderfer D, Solovieff N, Roussos P, O’Dushlaine C, Chambert K, Bergen SE, Kähler A, Duncan L, Stahl E, Genovese G, Fernández E, Collins MO, Komiyama NH, Choudhary IS, Magnusson PK, Banks E, Shakir K, et al. (2014) A polygenic burden of rare disruptive mutations in schizophrenia. Nature 506:185-190.

Qian Y, Song J, Ouyang Y, Han Q, Chen W, Zhao X, Xie Y, Chen Y, Yuan W, Fan C (2017) Advances in roles of miR-132 in the nervous system. Front Pharmacol 8:770.

Qiao H, Li MX, Xu C, Chen HB, An SC, Ma XM (2016) Dendritic spines in depression: what we learned from animal models. Neural Plast 2016: 8056370 .

Ressler KJ, Mercer KB, Bradley B, Jovanovic T, Mahan A, Kerley K, Norrholm SD, Kilaru V, Smith AK, Myers AJ, Ramirez M, Engel A, Hammack SE, Toufexis D, Braas KM, Binder EB, May V (2011) Post-traumatic stress disorder is associated with PACAP and the PAC1 receptor. Nature 470:492-497.

Retamales-Ortega R, Oróstica L, Vera C, Cuevas P, Hernández A, Hurtado I, Vega M, Romero C (2017) Role of nerve growth factor (NGF) and miRNAs in epithelial ovarian cancer. Int J Mol Sci 18:E507.

Roser AE, Caldi Gomes L, Halder R, Jain G, Maass F, Tönges L, Tatenhorst L,
Bähr M, Fischer A, Lingor P (2018) miR-182-5p and miR-183-5p act as GDNF mimics in dopaminergic midbrain neurons. Mol Ther Nucleic Acids 11:9-22.

Sakai Y, Hashimoto H, Shintani N, Ichibori A, Tomimoto S, Tanaka K, Hirose $\mathrm{M}$, Baba A (2002) Involvement of intracellular $\mathrm{Ca}^{2+}$ elevation but not cyclic AMP in PACAP-induced p38 MAP kinase activation in PC12 cells. Regul Pept 109:149-153.

Schratt G (2009) microRNAs at the synapse. Nat Rev Neurosci 10:842-849.

Schratt GM, Nigh EA, Chen WG, Hu L, Greenberg ME (2004) BDNF regulates the translation of a select group of mRNAs by a mammalian target of rapamycin-phosphatidylinositol3-kinase-dependent pathway during neuronal development. J Neurosci 24:7366-7377.

Schratt GM, Tuebing F, Nigh EA, Kane CG, Sabatini ME, Kiebler M, Greenberg ME (2006) A brain-specific microRNA regulates dendritic spine development. Nature 439:283-289.

Serita T, Fukushima H, Kida S (2017) Constitutive activation of CREB in mice enhances temporal association learning and increases hippocampal CA1 neuronal spine density and complexity Sci Rep 7:42528.

Shibasaki Y, Hayata-Takano A, Hazama K, Nakazawa T, Shintani N, Kasai A, Nagayasu K, Hashimoto R, Tanida M, Katayama T, Matsuzaki S, Yamada K, Taniike M, Onaka Y, Ago Y, Waschek JA, Köves K, Reglödi D, Tamas A, Matsuda T, et al. (2015) Atomoxetine reverses locomotor hyperactivity, impaired novel object recognition, and prepulse inhibition impairment in mice lacking pituitary adenylate cyclase-activating polypeptide. Neuroscience 297:95-104.

Soreq H, Wolf Y (2011) NeurimmiRs: microRNAs in the neuroimmune interface. Trends Mol Med 17:548-555.

Tajiri M, Hayata-Takano A, Seiriki K, Ogata K, Hazama K, Shintani N, Baba A, Hashimoto H (2012) Serotonin 5-HT(7) receptor blockade reverses behavioral abnormalities in PACAP-deficient mice and receptor activation promotes neurite extension in primary embryonic hippocampal neurons: therapeutic implications for psychiatric disorders. J Mol Neurosci 48:473-481.

Tanaka K, Shintani N, Hashimoto H, Kawagishi N, Ago Y, Matsuda T, Hashimoto R, Kunugi H, Yamamoto A, Kawaguchi C, Shimada T, Baba A (2006) Psychostimulant-induced attenuation of hyperactivity and prepulse inhibition deficits in Adcyap1-deficient mice. J Neurosci 26:50915097.

Wayman GA, Davare M, Ando H, Fortin D, Varlamova O, Cheng HY, Marks D, Obrietan K, Soderling TR, Goodman RH, Impey S (2008) An activity-regulated microRNA controls dendritic plasticity by downregulating p250GAP. Proc Natl Acad Sci U S A 105:9093-9098.

Xu W (2011) PSD-95-like membrane associated guanylate kinases (PSDMAGUKs) and synaptic plasticity. Curr Opin Neurobiol 21:306-312.

Xu X, Miller EC, Pozzo-Miller L (2014) Dendritic spine dysgenesis in Rett syndrome. Front Neuroanat 8:97.

Yaka R, He DY, Phamluong K, Ron D (2003) Pituitary adenylate cyclaseactivating polypeptide (PACAP(1-38)) enhances N-methyl-D-aspartate receptor function and brain-derived neurotrophic factor expression via RACK1. J Biol Chem 278:9630-9638.

Ye Y, Xu H, Su X, He X (2016) Role of MicroRNA in governing synaptic plasticity. Neural Plast 2016:4959523.

Yoshii A, Constantine-Paton M (2010) Postsynaptic BDNF-TrkB signaling in synapse maturation, plasticity, and disease. Dev Neurobiol 70:304322. 